\title{
El sistema de torres musulmanas en tapial de la Sierra de Segura (Jaén). Una contribución al estudio del mundo rural y el paisaje de al-Andalus ${ }^{1}$
}

\author{
The system of Muslim towers built with rammed earth in the Sierra de Segura \\ (Jaén). A contribution to the study of the rural world and landscape of al-Andalus
}

\author{
Santiago Quesada-García ${ }^{2}$, Guadalupe Romero-Vergara ${ }^{3}$ \\ Escuela Técnica Superior de Arquitectura, Universidad de Sevilla
}

\begin{abstract}
RESUMEN
En el límite entre garb al-Andalus y šharq al-Andalus se ubica el valle formado por los ríos Guadalimar, Hornos y Trujala en la Sierra de Segura (Jaén). Un territorio en el que se unían los antiguos caminos medievales que llegaban de Sevilla (Ishibiya) y Granada (Gharnatah) para partir hacia Valencia (Balansiyya). En ese lugar aún subsiste un articulado sistema de torres de origen musulmán construidas en tapial durante el siglo XII. Este trabajo se centra en analizar sus características territoriales, formales y constructivas con el objetivo de documentarlas, establecer su cronología y proponer hipótesis sobre cuáles fueron sus usos y criterios de implantación. Para ello se contextualizan en su ámbito histórico y geográfico, se comparan con ejemplos peninsulares similares, se examinan los hallazgos obtenidos en la investigación y se extraen conclusiones que podrán ser aplicadas a la caracterización de asentamientos y arquitecturas rurales del paisaje de al-Andalus.
\end{abstract}

Palabras clave: paisaje; asentamientos rurales medievales islámicos; torres; tapial; técnicas constructivas almohades.

\begin{abstract}
On the border between garb al-Andalus and šharq al-Andalus lies the valley of the Guadalimar, Hornos and Trujala rivers in the Sierra de Segura (Jaén, Spain). In this territory the old medieval roads that came from Seville (Ishibiya) and Granada (Gharnatah) joined to go towards Valencia (Balansiyya). Here, there is still an articulated system of towers of Muslim origin built in rammed earth during $12^{\text {th }}$ century. This work focuses on analysing and determining their territorial, formal, technical and constructive characteristics with the goal of documenting those structures of rammed earth, establishing their chronology and proposing hypotheses about their uses and criteria for territory implementation. For these purposes, they are contextualized in their historical and geographical scope and compared with similar peninsular examples. The data and results obtained in the research are examined and conclusions are drawn that can be applied to the characterization of rural settlements and landscape in al-Andalus.
\end{abstract}

Key words: landscape; rural Muslim Medieval settlements; towers; rammed-earth; Almohad constructive techniques.

Recibido: 31-03-2018. Aceptado: 12-07-2018. Publicado online: 04-07-2019

Cómo citar este artículo / Citation

Quesada-García, S. y Romero-Vergara, G. 2019: "El sistema de torres musulmanas en tapial de la Sierra de Segura (Jaén). Una contribución al estudio del mundo rural y el paisaje de al-Andalus", Arqueología de la Arquitectura, 16: e079. https://doi.org/10.3989/arq.arqt.2019.001

Copyright: (c) CSIC, 2019. (c) UPV/EHU Press, 2019. Este es un artículo de acceso abierto distribuido bajo los términos de la licencia de uso y distribución Creative Commons Reconocimiento 4.0 Internacional (CC BY 4.0).

\footnotetext{
1 Este trabajo ha sido posible gracias a la investigación realizada en el marco del Programa Estatal de Investigación, Desarrollo e Innovación Orientada a los Retos de la Sociedad, dentro del Plan Estatal de Investigación Científica y Técnica y de Innovación 2013-2016, con el proyecto HAR2014-53866-R titulado “El sistema de torres de origen medieval islámico en Segura de la Sierra, implantación, técnicas constructivas y restauración del tapial”. Además ha tenido como antecedente otro proyecto de investigación pre-competitivo de la Universidad de Málaga denominado: "La construcción de un paisaje: arquitectura de tapial en la Alta Andalucía en el siglo XIII. Estudio y análisis del sistema de torres andalusíes en el valle de Segura de la Sierra", obtenidos y dirigidos ambos por Santiago Quesada-García.

2 sqg@us.es / ORCID iD: https://orcid.org/0000-0002-6108-459X

gromero3@us.es / ORCID iD: https://orcid.org/0000-0001-5854-4682
} 
En el territorio musulmán de la península ibérica, durante la Edad Media, la construcción con tierra apisonada o tapia (tâbiya) llegó a su máximo desarrollo. Frente al uso de la mampostería y cantería de épocas anteriores, el tapial fue la técnica preferentemente utilizada en determinados tipos de construcción por el gobierno de los almohades o "unitarios" ${ }^{4}$ durante su expansión hacia el Levante peninsular. Esta circunstancia fue debida a que era una práctica conocida e importada de su lugar de procedencia pero, sobre todo, a su versatilidad, su rápida puesta en obra y la economía de medios que suponía la extracción in situ de la materia prima necesaria para la construcción. De la importancia que tuvo este sistema constructivo da cuenta la gran cantidad de arquitectura en tapia que aún se conserva en el antiguo territorio de al-Andalus.

Entre las numerosas edificaciones realizadas con esta técnica constructiva, además de los conocidos recintos amurallados, alcazabas, almudainas, cubos, barbacanas y construcciones que se podrían denominar dinásticas, existen también numerosos elementos dispersos en el territorio asociados a asentamientos rurales de explotación de la tierra, a funciones estratégicodefensivas o a control territorial y fiscal por parte del Estado musulmán. El gran número de ejemplares de este tipo de inmuebles diseminados, aún existente en el sur y este de la península ibérica, hace necesaria una revisión y relectura del conjunto, no tanto para realizar

\footnotetext{
4 Al-Muwahhidun quiere decir "aquellos que reconocen la unidad de Dios" por ello los almohades son también conocidos como los Unitarios.
}

una nueva clasificación y caracterización de sus fábricas, sino para ponerlos en relación entre sí y conocer aspectos poco analizados de este tipo de edificaciones dispersas. Todavía hay muchos interrogantes sobre cuáles eran las características de estas estructuras rurales, cómo eran sus criterios de implantacion, qué elementos las formaban y qué funciones tenían.

Este artículo aborda el estudio de un conjunto de construcciones en tapial existentes en el valle de los ríos Guadalimar, Trujala y Hornos en la Sierra de Segura (Fig. 1). La mayoría de ellas son torres localizadas en la parte baja del valle, estructuras aisladas y diseminadas que no pertenecen a castillos (husūn); tampoco están ubicadas en los puntos más altos del terreno, es decir, no son atalayas que dan aviso de lo que se descubre en la lejanía ${ }^{5}$.

El objetivo del trabajo es encontrar rasgos característicos de esas torres, comprobar su forma de ocupación en el territorio, aportar datos sobre su cronología, sus características técnicas y constructivas y poder establecer puntos en común con ejemplos similares existentes en otros lugares de al-Andalus. Para ello, se propone un recorrido que primero establece el estado de la cuestión en relación a la arquitectura en tapia, después presenta el método y herramientas con las que se ha realizado la investigación. A posteriori, contextualiza históricamente la difusión de la técnica de tapial en el territorio

\footnotetext{
La definición que el DRAE da al término atalaya, que procede del árabe hispánico atțaláya', es torre hecha comúnmente en lugar alto, para registrar desde ella el campo o el mar y dar aviso de lo que se descubre.
}
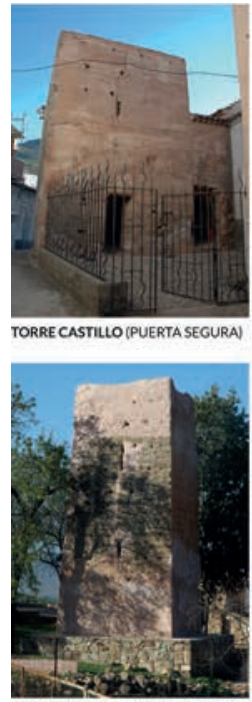

TORRE PENOUTE (PUENTE GENAVE
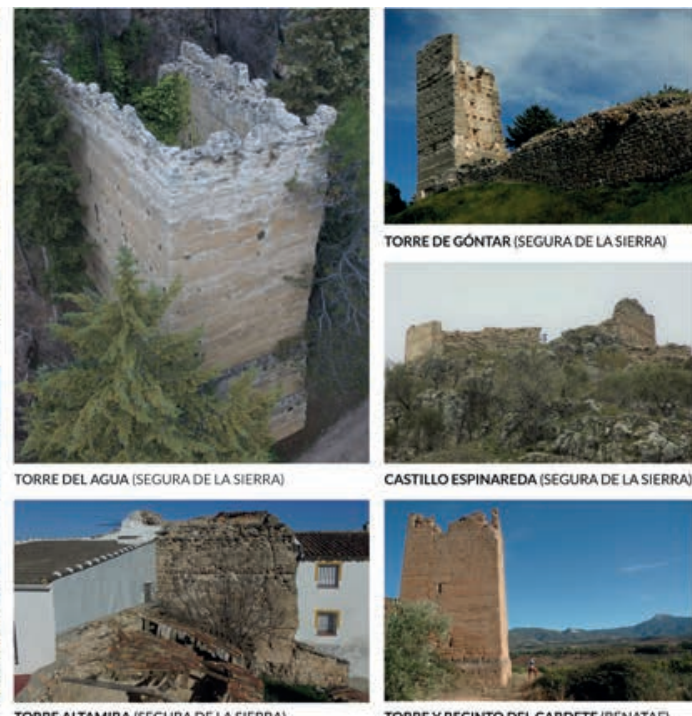

TORRE YRECINTO DEL CARDETE [BENATAE

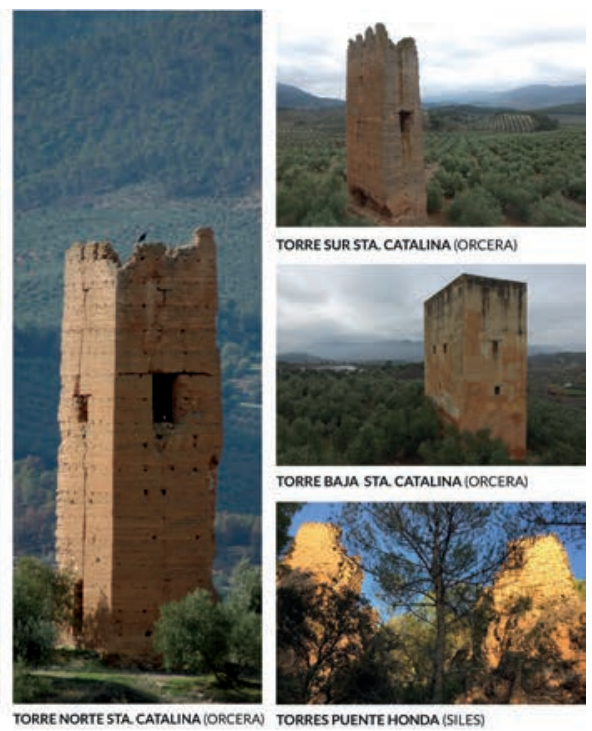

Figura 1. Conjunto de torres de tapial existentes en el valle de los ríos Guadalimar, Hornos y Trujala en la Sierra de Segura (Jaén). Fuente: autor. 
peninsular, centrando la mirada en las características de los asentamientos rurales andalusíes. Para finalizar, el artículo se focaliza en el sistema de torres jiennense, exponiendo los datos y resultados obtenidos en las indagaciones realizadas. Las conclusiones intentan aportar alguna luz y conocimiento sobre estos restos dispersos construidos en tapial en ese rincón de al-Andalus.

\section{ESTADO DE LA CUESTIÓN}

Como en tantos otros aspectos de la arquitectura y el urbanismo andalusí, el precursor del estudio de la arquitectura en tapia fue Leopoldo Torres Balbás, conservador de la Alhambra entre 1922 y 1936. Este arquitecto publicó una serie de libros sobre ciudades hispano-musulmanas (Torres Balbás 1985) así como una serie de trabajos en los que ponía de relieve las construcciones en tierra a partir de las conclusiones obtenidas durante años de intervención directa en la restauración del monumento granadino.

A mediados de la década de los noventa del pasado siglo hubo un resurgir de las investigaciones dedicadas a la arquitectura defensiva y militar. Los trabajos del medievalista francés André Bazzana (1980) sobre la organización del territorio musulmán y sus tipologías de asentamientos y poblaciones, comenzaron a evidenciar el retorno del interés científico por la cultura islámica en al-Andalus y, en concreto, por el periodo almohade (Acién 1995, Pavón Maldonado 1999).

Posteriormente, se comenzaron a desarrollar una serie de iniciativas promovidas por el Departamento de Estudios Árabes del CSIC, la Casa de Velázquez y algunas universidades francesas como Lumiére-Lyon $2 \mathrm{y}$ Toulouse (Cressier et al. 2005), que fructificaron en varios seminarios y eventos científicos basados en hallazgos arqueológicos, fuentes historiográficas y crónicas históricas. Fue con este impulso cuando comenzaron a surgir numerosas publicaciones relacionadas con las construcciones almohades. Se comenzaron a estudiar los falsos despieces de sillería de sus paramentos (Azuar 1994; Azuar et al. 1996), las técnicas constructivas (Gurriarán y Saéz 2002) o las fortificaciones defensivas almohades en la provincia de Sevilla (Valor 2004a, 2004b).

Estas investigaciones dieron lugar, a partir de 2005, a otro tipo de trabajos, unas veces consecuencia de estudios previos de diagnosis realizados en proyectos de consolidación y otras como resultado del desarrollo de tesis doctorales. En el ámbito académico, la arquitectura en tierra apisonada ha sido objeto de clasificación atendiendo a distintos criterios que unían la caracterización material con el análisis constructivo (Tabales 2001; Azuar 2004; Jaquin et al. 2008; Graciani y Tabales 2008; Mileto et al. 2013; Gil-Crespo 2016). Son estudios de mucha intensidad y casi siempre centrados en ordenar la fábrica de tapial desde su función, técnica, métrica y técnica constructiva, con toma de datos y muestras normalmente cercanas al ámbito geográfico de los investigadores.

En el área de la provincia de Zaragoza, Jaquin, Augarde y Gerrard (2008) estudian un conjunto de más de cincuenta edificios construidos en tapial, y hacen una caracterización histórica por medio de una clasificación en diez tipos diferentes. Ignacio Gil-Crespo (2012) estudia ejemplos y casos en el territorio de Castilla-León y propone una nueva clasificación taxonómica, cuya intención es tener en cuenta todos los elementos que intervienen en esta técnica constructiva. En Castilla-La Mancha destacan los trabajos de investigación de David Gallego y Francisco Javier Castilla (Gallego et al. 2016). En las tierras de Alcaraz, cuenca del rio Segura y llanos de Albacete, sobresale el trabajo de documentación y catalogación realizado por José Luis Simón García (2011).

En el Levante se han realizado estudios constructivos sobre el tapial de fortificaciones ubicadas en el antiguo šharq al-Andalus (Soler 2009). En esa región destacan los trabajos liderados por Camilla Mileto y Fernando Vegas que, basándose en ejemplos cercanos, definen una clasificación en subcategorías en base a los invariantes y variantes que se repiten en las fábricas de tapia. Estos investigadores también realizan propuestas de intervención en la arquitectura en tapia basandose en sus criterios analíticos (Mileto et al. 2012, 2013, 2017). En el antiguo reino hudí de Murcia, el arquitecto Francisco J. López Martínez estudia e investiga, en su tesis doctoral y en los proyectos de intervención que realiza, las fábricas de tapiales existentes en dicha provincia (López Martínez 1999, 2012; López Martínez y Martínez López 1999).

En el entorno sevillano, Tabales (2001) realizó una primera clasificación preliminar que culminó con doce tipos de tapia distintos. Esta clasificación fue sistematizada posteriormente por Graciani y Tabales (2008) proponiendo una clasificación cronotipológica que tiene en cuenta la distinción entre tapias mixtas y monolíticas (Graciani et al. 2005). Otras contribuciones que destacan en el ámbito geográfico de Andalucía Occidental son los trabajos de Barrios, Graciani y Núñez (2012) o los de Canivell y Graciani (2015) que establecen un 
método para conocer los procesos de construcción por medio de la caracterización de las fábricas a partir de determinadas variables como las históricas, sociales o culturales. En la zona de la campiña cordobesa destacan los estudios sobre torres islámicas de Martínez Castro (Martínez y Tristell 1998; Martínez 2003, 2015), en alguno de ellos analiza la alquería como unidad de poblamiento básico en al-Andalus (Martínez 2005).

En Andalucía Oriental, Martín García y Martín Civantos $(2000,2011)$ estudian el poniente almeriense y la provincia de Granada. Sobre las fortificaciones jiennenses hay una amplia y extensa bibliografía (Eslava 1989, 1999; Cerezo y Eslava 1989; Pavón Maldonado 1998; Salvatierra 1999). En esta provincia andaluza, zona de paso entre garb al-Andalus y šharq al-Andalus y frontera con los reinos cristianos durante más doscientos años, existen abundantes ejemplos de construcciones realizadas en tapia, no solo en murallas de ciudades y castillos, como el de Burgalimar en Baños de la Encina, sino en numerosos elementos rurales dispersos.

En la comarca de la Sierra de Segura en el noreste jiennense existen varios estudios e investigaciones que abordan la evolución y poblamiento del valle de los ríos Hornos y Trujala (Salvatierra y Visedo 2008) incluyendo una descripción de las construcciones medievales existentes en la zona (Salvatierra et al. 2006). En los últimos años, el sistema de construcciones en tapial del valle está siendo estudiado por Santiago QuesadaGarcía quien, a raiz de los proyectos de consolidación en algunas torres, ha realizado estudios de diagnóstico y ensayos de materiales, analizando su estado de conservación, los aspectos arquitectónicos, estructurales, constructivos, caracterizando las fábricas de tapial (QuesadaGarcía y García-Pulido 2013, 2015a, 2015b, 2017).

El presente trabajo pretende complementar y profundizar en los anteriores estudios sobre las torres de la Sierra de Segura, abordando el análisis de estas arquitecturas musulmanas diseminadas, no tanto desde la clasificación taxonómica de sus fábricas sino desde su implantación y organización en el territorio, aportando nuevos datos que puedan servir para conocer cuáles eran sus funciones así como los criterios con los que estos elementos se ubicaban espacialmente articulando la ocupación y explotación de la tierra (Fig. 2).

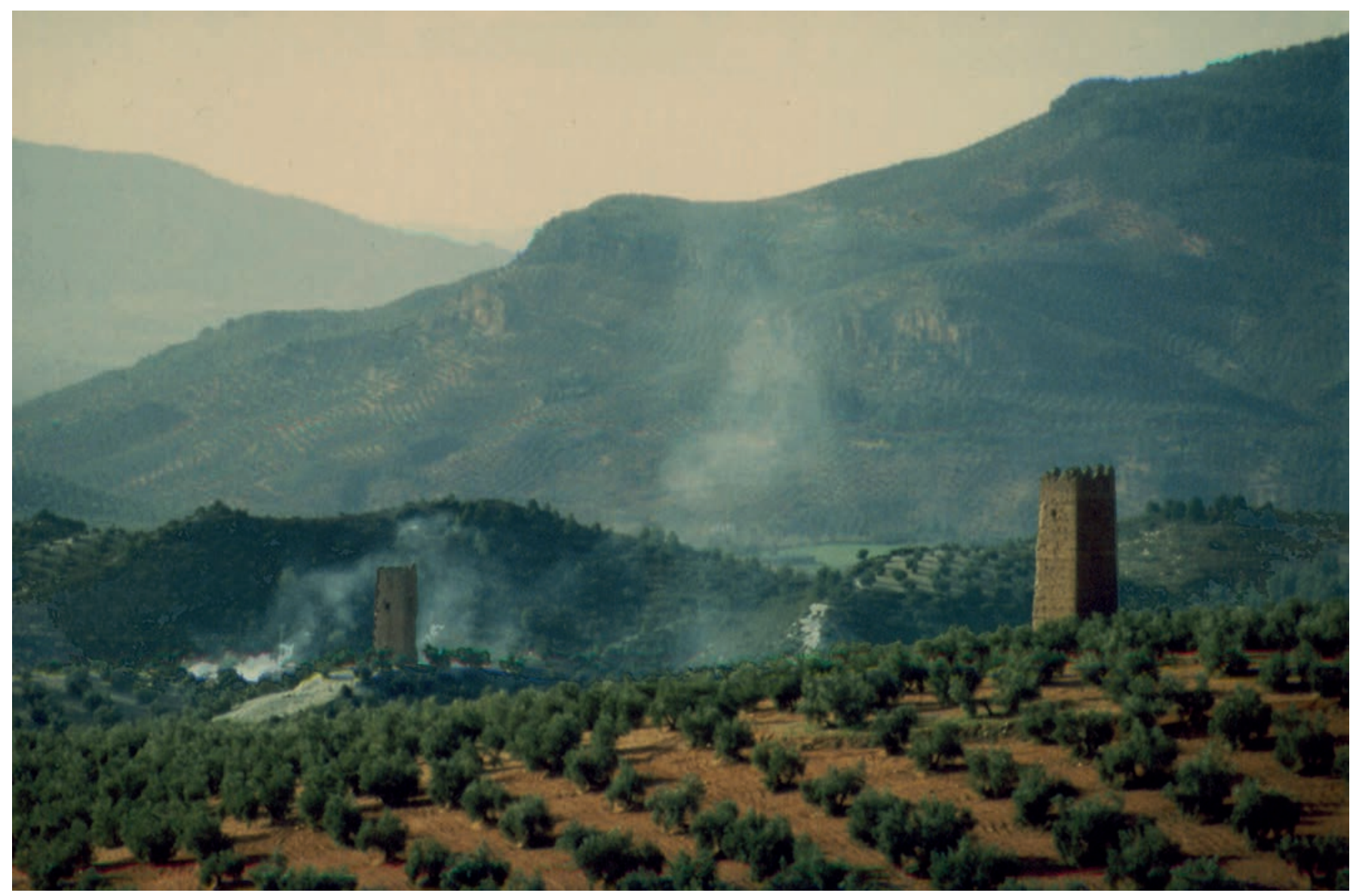

Figura 2. Torre norte y torre sur de Sta. Catalina en Orcera (Jaén). Fuente: autor. 


\section{OBJETIVO, MÉTODO Y HERRAMIENTAS EMPLEADAS}

En el epígrafe anterior se ha visto cómo gran parte de los últimos estudios sobre la tapia se han centrado en estudiar la técnica constructiva y en determinar una clasificación taxonómica de las fábricas de tapial de una zona geográfica concreta. Por otro lado, hay excelentes estudios que abordan la problemática territorial en época medieval y, en concreto, sobre los modos de asentamiento y las unidades de poblamiento en el ámbito rural de al-Andalus (Bazzana 1980, 2009; Guichard 1988; Cressier 1987, 1991; Acién 2008; Azuar 2008; Malpica 2003; Pérez Aguilar 2013). Sin embargo, en relación a la jerarquización socio-económica y territorial andalusí todavía quedan muchos aspectos y matices por conocer y entender ya que, en muchas ocasiones, no se dispone de fuentes literarias o documentales suficientes, se carece de actuaciones arqueológicas o no se ha pasado de un primer nivel de reconocimiento (Malpica 2006: 200). En el caso concreto de los asentamientos rurales es necesario un análisis detallado del mayor número de variables para determinar cómo y cuáles eran los tipos existentes en al-Andalus, ya que para conocer una realidad primero hay que describirla (Malpica 1999: 148). Este es el principal objetivo de este artículo.

Las indagaciones sobre las fábricas de tapial de la Sierra de Segura comenzaron en el año 2003 y decantaron diez años más tarde en sendos proyectos de investigación ${ }^{6}$. La metodología de trabajo que se está empleando utiliza la revisión de fuentes y referencias bibliográficas, imprescindibles para el conocimiento de este periodo medieval islámico, pero las principales fuentes primarias que se están usando son los inmuebles

\footnotetext{
El primer acercamiento a estas torres construidas en tapial de la Sierra de Segura tuvo lugar en el año 2003 con el levantamiento y restitución fotogramétrica de la torre del Cardete (Benatae), las torres norte y sur de Santa Catalina (Orcera), torre de Góntar y la torre del Agua (Segura de la Sierra). Posteriormente el estudio de la técnica constructiva se produjo en 2006 con la redacción de los proyectos de restauración y consolidación de las dos torres de Santa Catalina y de las torres de Gontar y del Agua. Estos primeros trabajos dieron lugar, posteriormente, a varios proyectos de investigación dirigidos por Santiago Quesada-García. El primero de ellos fue un proyecto de investigación precompetitivo concedido por la Universidad de Málaga titulado: "La construcción de un paisaje: arquitectura de tapial en la Alta Andalucía en el siglo XIII. Estudio y análisis del sistema de torres andalusíes en el valle de Segura de la Sierra”. El segundo proyecto, todavía en desarrollo, se denomina: "El sistema de torres de origen medieval islámico en Segura de la Sierra, implantación, técnicas constructivas y restauración del tapial" (HAR2014-53866-R), realizado dentro del Programa Estatal de Investigación, Desarrollo e Innovación Orientada a los Retos de la Sociedad ( 2013-2016) del Ministerio de Economía, Industria y Competitividad.
}

y restos que todavía se conservan sobre el terreno. Por tanto, el trabajo que aquí se expone está basado, en su integridad, en el estudio de fuentes materiales, en la documentación que aportan las propias torres, auténticos fósiles históricos que han sobrevivido prácticamente inalterados desde el momento de su construcción. La investigación también se basa en la lectura analítica del territorio y la información que facilita el entorno de estos restos con el objetivo de extraer, describir y análizar los datos que aporta el espacio físico del sistema de torres para así conocer sus diferentes variables, comunes y divergentes, con las que determinar patrones y pautas que permitan comparar con otros elementos rurales de al-Andalus. A partir de ahí, se interpretan los resultados obtenidos y se intenta establecer algunas de las formas de establecimiento de la arquitectura rural islámica de este período. El proceso, técnicas y herramientas empleadas en la investigación ha sido:

1. Toma de datos in situ y extracción de muestras. La recolección de datos ha sido en primer lugar por medio de la realización de fotos, videos, croquis y dibujos al natural. Posteriormente se han hecho mediciones con estación total topográfica así como distanciómetro láser. La nube de puntos terrestre ha sido completada con otra obtenida a partir de un dron. Con las muestras de materiales se han efectuado ensayos de dendrocronología y radiocarbono, así como pruebas físicas y químicas para determinar la composición y naturaleza de los elementos que componen las fábricas.

2. Análisis del ámbito territorial, orográfico y topográfico. El territorio contiene la memoria de las marcas dejadas por ocupaciones anteriores y está constituido por estratificaciones sucesivas. La cartografía permite acercarse con exactitud al análisis de la implantación de las torres, su relación con otras estructuras productivas, caminos históricos, obras de infraestructura y trazados hidráulicos. Por ello, se ha realizado un inventario de mapas y fotos aéreas de la zona, un estudio comparativo de mapas históricos y, sobre todo, una lectura macroespacial del territorio del valle, su orografía, red hidráulica y sistema de infraestructuras para conocer en profundidad cómo ha sido su ocupación y explotación. Se han generado planimetrías a escala 1:30.000 de la zona objeto de estudio y elaborado Modelos Digitales del Terreno (MDT) que han permitido una representación orográfica del entornos de las estructuras de tapial (Fig. 3). 

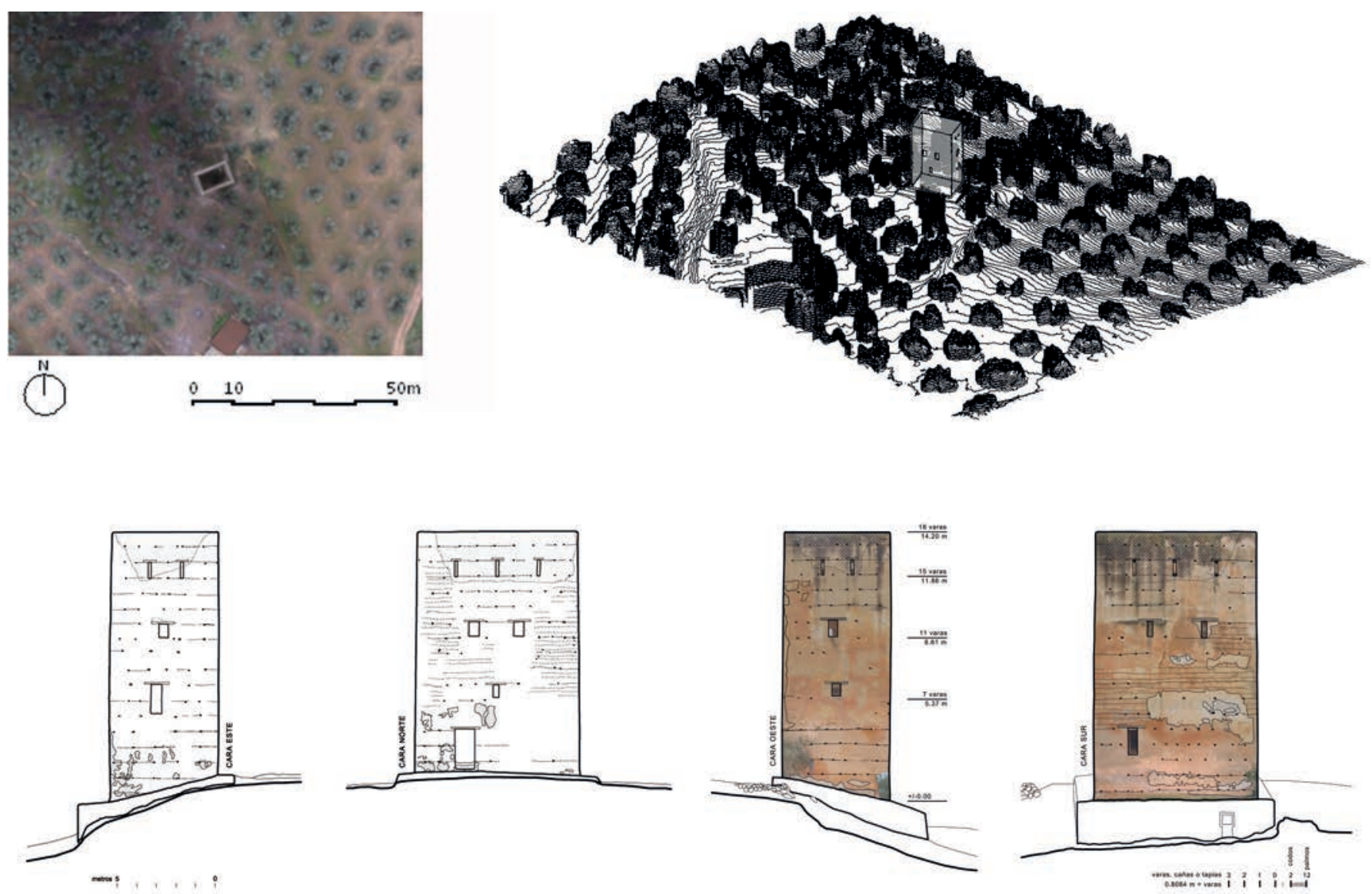

Figura 3. Levantamiento fotogramétrico de la torre baja de Sta Catalina (Orcera) y Modelo Digital del Terreno 3D del entorno. Es un material realizado combinando: toma de datos con croquis, distanciometro laser, cintas, estación total y drones. Fuente: elaboración propia.

Por otro lado, se han seleccionado diferentes áreas del antiguo territorio de al-Andalus en las que todavía existen elementos de arquitectura similares con el fin de realizar una comparación entre sus formas de implantación. Se han individualizado tres zonas concretas: el Bajo Guadalquivir (campiña de Córdoba), el Alto Guadalquivir (valle de ríos Guadalimar, Hornos y Trujala en la Sierra de Segura) y, por último, la cuenca del Turia y Sierra Calderona en Valencia además del condado de Cocentaina en Alicante.

De cada uno de los entornos de las torres de Segura se han realizado los levantamientos topográficos individualizados a escala 1:500, en casos singulares también a escala 1:200. El objetivo ha sido dibujar e interpretar con precisión sus contextos y detectar posibles permanencias o trazados ocultos por procesos urbanísticos, plantaciones de olivos, balsas de agua, encauzamientos de ríos, carreteras, canteras, erosiones y otras alteraciones antrópicas y naturales (Fig. 4).
3. Redacción de conclusiones interpretativas, textuales y gráficas. Se ha procedido al levantamiento fotogramétrico de los inmuebles dibujando las plantas, secciones y alzados de cada torre. La planimetría fotogramétrica generada tiene un nivel de detalle equivalente a la escala 1:50. Posteriormente se ha hecho un estudio estratigráfico de los paramentos más significativos aplicando la matriz de Harris. La lectura estratigráfica se ha centrado en el estudio de las diferentes unidades de cada elemento, analizando la puesta en obra de los tapiales, su modulación y técnica constructiva empleada. Este trabajo ha permitido acotar todos los inmuebles en cajas/tapias y metros haciendo una interpretación formal y volumétrica de cada estructura. Además se han analizado, verificado y relacionado con los resultados obtenidos en las pruebas físicas, químicas y de radiocarbono 14 .

4. La última parte de la investigación, actualmente en proceso, realiza una parametrización y georreferenciación de todos los datos, materiales y elementos obtenidos en cada una de las torres a través de bases 


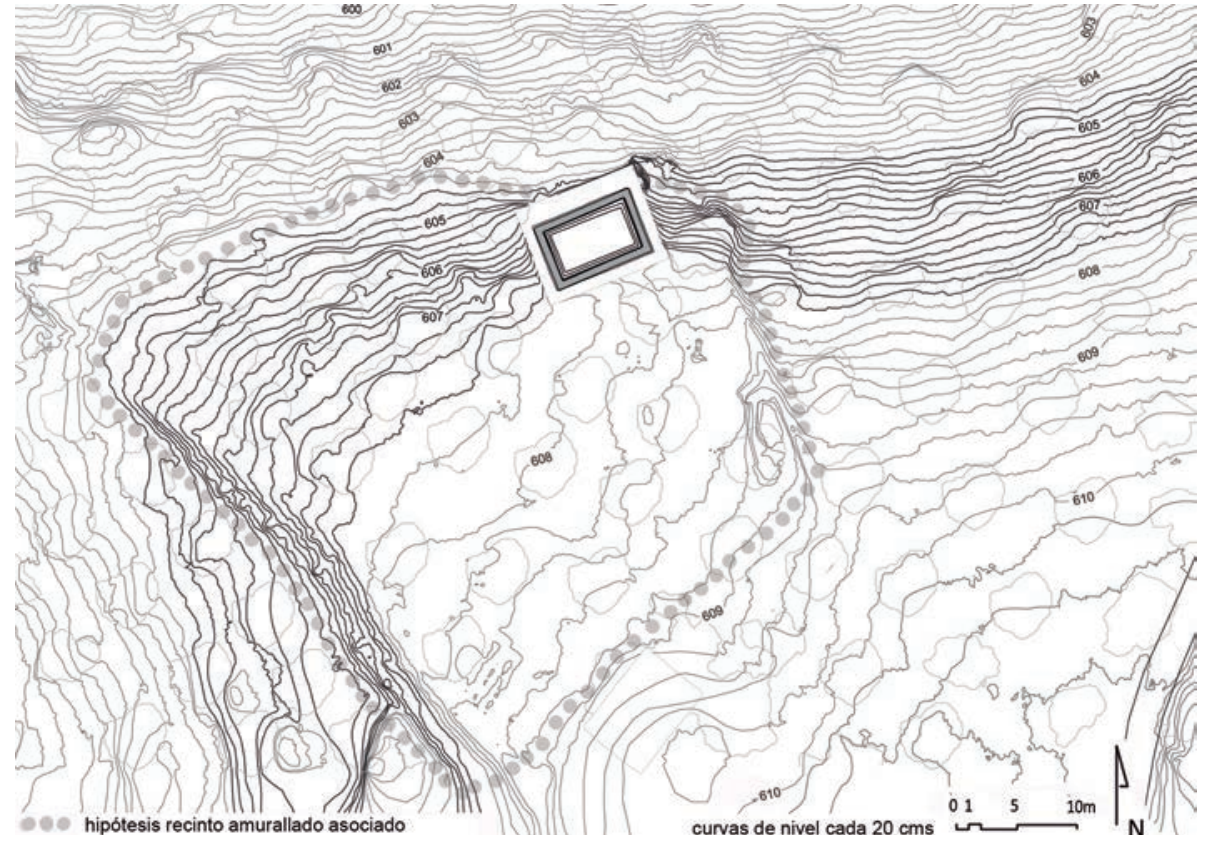

Figura 4. Levantamiento topográfico de la torre baja de Sta Catalina con una hipótesis del trazado del posible recinto asociado a la torre. Fuente: elaboración propia. de datos procesadas mediante aplicaciones SIG para facilitar su integración, análisis y difusión a una información que estará disponible en open data.

\section{DE LAS ALCAZABAS A LAS ALQUERÍAS, LA DEPURACIÓN DE UNA TÉCNICA}

Para analizar y entender estas construcciones rurales en tierra es necesario conocer el proceso de evolución de las marcas fronterizas en la península ibérica entre los siglos XI y XIII, estudiar la distribución espacial de los asentamientos rurales en el territorio, contextualizar sus características constructivas y conocer cuál ha sido la evolución de la técnica del tapial desde las primeras construcciones del Califato Omeya de Córdoba (929-1031), los reinos de taifas (1032-1085), la invasión almorávide (1086-1144), hasta llegar al imperio almohade (11451228), época de máximo esplendor y utilización de esta técnica constructiva.

En los primeros momentos de la implantación del islam en la península ibérica, el uso de la cantería era normal en la mayoría de las construcciones oficiales omeyas, casi como la continuidad de una tradición bien establecida en Hispania durante época romana y visigoda. Los muros construidos con sillares a soga y tizón son habituales desde el siglo VIII hasta bien entrado el siglo XII, en plena época almorávide. Tras la fundación de Almería y su castillo, en el año 955, se construyó en al-Andalus una línea de fortalezas en el corto período de tiempo comprendido entre el final del reinado de Abd al-Rahmān III y el comienzo del califa al-Ḥakam II. Entre estas fortificaciones se encuentran los castillos de Tarifa (Cádiz) y Gormaz (Soria), recintos amurallados construidos en piedra. El uso del tapial en construcciones de este periodo era poco frecuente, aunque está atestiguado en las inmediaciones de Córdoba en la almunia ${ }^{7}$ (al-munya) de Rumaniyya, e incluso podría haberse utilizado en las partes superiores de la muralla de Madīnat al-Zahra, construida por Abd al-Rahmān III y al-Ḥakam II. También se empleó en el relleno interior de muros de sillares en algunas ciudadesfortalezas como Vascos en la provincia de Toledo.

A lo largo del siglo IX, la construcción con la técnica del tapial posibilitó a grupos enfrentados entre sí levantar fortalezas en poco tiempo y con pocos recursos, dado que esta práctica era más accesible e inmediata que el trabajo con mampostería de sillares ya que la tierra podía encontrarse como materia prima fácilmente, no necesitaba transporte y era un tipo de construcción que no requería excesiva especialización (Azuar 1994: 135). Uno de los ejemplos de este siglo se encuentra en Calatayud (Qal'at Ayyub) que data del 884-885. El relleno de tapial también es visible en partes de las murallas del castillo de La Muela en Ágreda (Soria) construidas en el siglo X. Otros ejemplos existentes en la frontera norte con Castilla y construidos con muros en tapial se encuentran en Talamanca del Jarama, provincia

\footnotetext{
Este término se refiere a una finca de recreo con huertos, normalmente, vinculada a las élites de poder.
} 
de Madrid, Medinaceli en Soria o Ayllón en Segovia (Zamora 2008).

La inestabilidad económica y política de los reinos de taifas, significó el refuerzo de la arquitectura defensiva del período anterior (Terrasse 1954). Las obras de cantería, tan características en las fortalezas previas, comenzaron a ser sustituidas por el uso del tapial. En la ciudad de Murcia, así como en el castillo y palacio taifa de Onda (Castellón) se ha documentado la construcción de muros de tierra apisonada sobre zócalos de piedra con poca cal. Se trata de elementos a menudo reforzados y muy reconstruidos (Navarro y Jímenez 2011; Navarro y Estall i Poles 2011).

En 1086, algunos reyes de estas taifas decidieron pedir auxilio al monarca almorávide de Marruecos, Yusūf ibn Tashfin, para que los defendiera contra Alfonso VI, rey de Castilla y León. La constante presión cristiana en las marcas hizo que, durante los siglos XI y XII, la prioridad fuera hacer obras urgentes en las fortificaciones. Ibn 'Idari describió en su Bayān la imposición de un impuesto en 1125, llamado ta 'tīb, para la reconstrucción de muros en ciudades como Córdoba, Sevilla y Granada. También se realizaron reparaciones en Almería, Écija, Jerez y Niebla ${ }^{8}$. Las numerosas obras realizadas en estas murallas en tiempos posteriores dificultan la lectura de los refuerzos indicados en textos coetáneos. En fortificaciones conservadas al otro lado del estrecho de Gibraltar, como las de Amergo y Zagora (Marruecos), en vez de tapia se empleó mampostería de tamaño mediano dispuesta en hiladas muy regulares. Por todas estas circunstancias el tapial en las construcciones almorávides de al-Andalus está siendo recientemente cuestionado.

Hacia 1144 estallaron una serie de revueltas en la península ibérica como consecuencia del descontento de la población andalusí respecto al gobierno almorávide. En este momento aparecieron señores de la guerra locales (muridín) más o menos autónomos. Fue un período que se ha considerado como el de los segundos reinos de taifas. Poco después, el imperio almohade expandió sus dominios desde la cordillera del Atlas hasta Sevilla, ciudad que se convirtió en su capital a este lado del estrecho de Gibraltar. Entre 1148 y 1151 los almohades ocuparían las tierras de Córdoba y Badajoz. El Levante peninsular sería controlado hacia 1157. La unificación política y militar de al-Andalus bajo los almohades no se completó hasta 1172 con el gobierno del segundo califa

\footnotetext{
8 Las murallas de esta última ciudad están bien conservadas, fueron construidas alrededor de 1130, tienen un perímetro de dos kilómetros que incluyen cincuenta torres rectangulares y dos octogonales.
}

Abū Ya'qūb Yusūf I (r. 1163-1184). A partir del último cuarto del siglo XII tras esa expansión, los almohades fortificaron las ciudades y los husūn (Huici 2000).

En šharq al-Andalus las murallas de la ciudad de Murcia fueron reforzadas, la mayor parte de los restos conservados de tapial datan del siglo XII, con alturas de cajón cercanas a los $85 \mathrm{~cm}$ (dos codos ma'mūn $\bar{l})$. Los restos de tapias anteriores tienen una altura de cajones en torno a los $110 \mathrm{~cm}$, es decir, están más cercanas al codo raššāšš ${ }^{9}$. Son construidas principalmente con tierra y poca cal (Navarro y Jiménez 2011: 85-120). Las murallas de Cartagena también fueron construidas entre finales del siglo XII y principios del XIII. Entre las medinas principales de $\dot{g} a r b$ al-Andalus habría construcciones en tapial en Sevilla, Badajoz, Cáceres, Juromenha o Alcácer do Sal (Alentejo, Portugal) (Fernandes y Correia 2005), Castelo Velho en Alcoutim, Paderne, Silves, Salir, Loulé, Tavira o Faro (Algarve, Portugal) (Pavón Maldonado 1993; Magalhães 2002: 174). Las dimensiones más comunes en las construcciones almohades de tapial están representadas en las murallas de Sevilla, con tapiales de $240-250 \mathrm{~cm}$ de longitud (6 codos) y $80-90 \mathrm{~cm}$ de altura (2 codos), agujas cada $82-85 \mathrm{~cm}$ y refuerzos de madera dentro de los muros (Valor 2009). El empleo de la técnica del tapial en murallas, fortalezas y construcciones se generalizó, siendo común en el siglo XIII. (Terrasse 1954). En la poliorcética de esta época también destaca la construcción en tapial de torres avanzadas poligonales, como las de Espantaperros en la alcazaba de Badajoz o la famosa Torre del Oro en Sevilla construida con refuerzos de sillería en 1221. Las fortalezas defendidas por antemuros y albarranas son características de época almohade y están asimismo construidas con la técnica de tierra apisonada (Torres Bálbas 1934).

En época almohade comenzó a desarrollarse una nueva variante de tapial que fue profusamente utilizada a partir de ese momento. Se trata de la llamada tapia calicostrada o acerada que consistía en muros de tierra apisonada con cal forrando el exterior. Esta construcción se realizaba compactando tongadas de tierra y grava sobre una capa de cal. El proceso provocaba que la cal se expandiera y se elevara por la cara exterior para crear una costra protectora. Este calicostrado se podía colocar en ambas caras del muro o solamente en la exterior.

\footnotetext{
9 "El codo raššăši equivale a un codo y cuarto, en relación con la medida del codo del brazo; este, a su vez, tiene dos palmos o veinticuatro dedos, y se le llama codo ma'mūní. El raššs̄assí, tiene treinta dedos y su uso fue establecido por el qassām de Córdoba 'Umar b. Raraŷal-Raššāšs, que grabó el patrón en una columna de la Aljama cordobesa”, de esta forma describe Ibn Luyūn en su Kitāb al-Filāha o Tratado de Agricultura las relaciones entre los diferentes codos y sus medidas (Eguaras 2014: 206).
} 
También se utilizó el tapial con brencas, consistente en su refuerzo con mortero de yeso y piedras, usualmente en huecos y jambas de puerta. Algunos de los ejemplos más claros de esta técnica pueden observarse en el despoblado almohade de Siyāsa (Cieza, Murcia) (Navarro y Jiménez 2011: 112-113). En época almohade, las agujas de madera dejaron de cruzar el espesor de los muros de tapial (Azuar y Ferreira 2014: 403) penetrando sólo una tercera o cuarta parte de la anchura del muro. Para sujetarlas, durante su puesta en obra, era necesario disponer de cuerdas anudadas a los barzones y clavarlas mediante cuñas de madera (Graciani 2009).

Una característica específica de esta arquitectura en tierra de origen almohade era realizar, en esa superficie calicostrada, dibujos y grafías simulando un despiece de sillería que servía de función protectora en las discontinuidades derivadas de la puesta en obra de la tapia, tapando mechinales y las juntas entre cajones (Azuar et al. 1996; Lozano et al. 1996; Azuar 2005; Márquez y Gurriarán 2008; Azuar y Ferreira 2014). La difusión de este motivo decorativo formaría parte del extenso programa de construcción, reconstrucción o ampliación de la arquitectura almohade, promovido por el segundo califa Yusūf I y el tercero al- Mansūr ${ }^{10}$ entre los años 1170 y 1200.

El cronista Ibn Sahib al-Sala, cuenta que Yusūf I encargó fortalecer Gibraltar, Córdoba y los castillos fronterizos, lo que confirmaría un programa de intervención en parte de las fortificaciones de al-Andalus. Otra crónica de Ibn Abi Zar ${ }^{11}$, relata que ese proyecto constructivo fue financiado por los recursos económicos procedentes del "quinto botín", obtenidos tras la victoria almohade en 1195 contra Alfonso VIII de Castilla en la batalla de Alarcos (Ciudad Real). Ingresos que habrían permitido al califa al-Mansūr promover una arquitectura con características constructivas y ornamentales representativas de la imagen y poder del Estado almohade.

Durante el gobierno del cuarto califa al-Nasîr (r. 11991213), los almohades fueron derrotados en la Batalla de las Navas de Tolosa (1212). Su declive comenzó con la muerte del quinto califa Abū Ya'qūb Yusūf II (r. 1213-1224) y, a partir de ese momento, algunas ciudades como Sevilla, Málaga, Murcia o Valencia comenzaron a reforzar sus murallas urbanas. En ese momento comenzaron a construirse algunos "graneros colectivos fortificados" para proteger las producciones de los cultivos. Tras la conquista de Valencia, en las montañas de Alicante comenzaron a aparecer lo que ha llegado a denominarse "castillos del miedo", construidos por las comunidades rurales que aún no habían sido conquistadas. Gran parte de ellos fueron demolidos pero en muchos lugares hay todavía referencias toponímicas a su existencia, como indica la abundancia del prefijo árabe burŷy (torre) (Fig. 5).

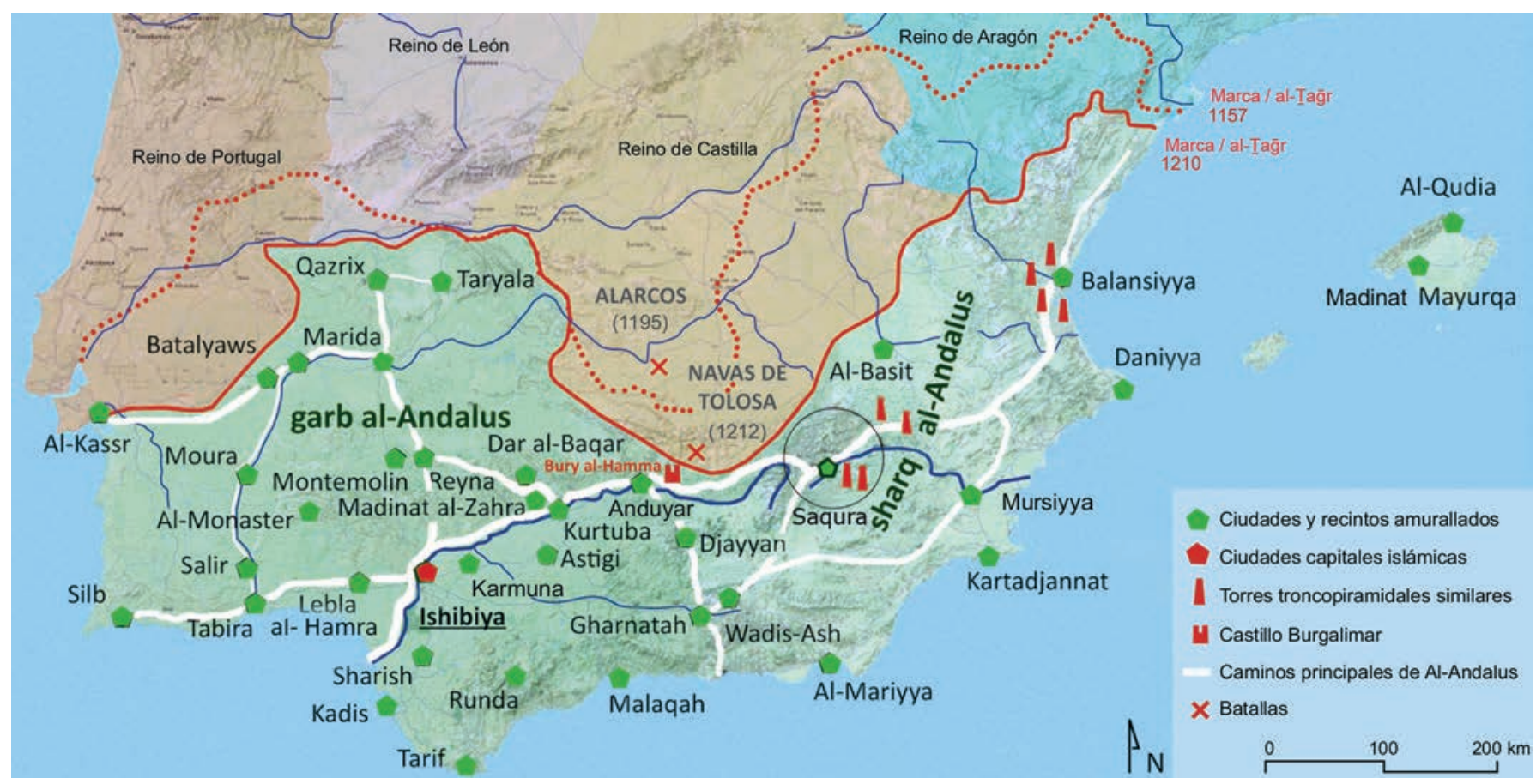

Figura 5. Principales ciudades y caminos de al-Andalus durante los siglos XII-XIII . Fuente: elaboración propia. 
Como consecuencia de esa inestabilidad política y militar y, a veces, de su situación estratégica en el territorio se fortificaron algunos centros de producción agrícola (Azuar 1981: 69-70; Manzano 1998) dotándose de torres, barreras o recintos amurallados más o menos amplios (Glick 1995: 13-15; Córdoba de la Llave 2003; Bazzana 2009), complementando de alguna forma el sistema defensivo andalusí formado por los husūn (Glick 2007). En la mayoría de los casos, el único elemento que se ha conservado de aquellas fortificaciones de núcleos rurales es la torre.

La depurada técnica constructiva de las torres rurales que han llegado hasta nuestros días parece indicar que estas fábricas tomaron como referente los modelos desarrollados en edificaciones dinásticas de más entidad como murallas, alcazabas o torres albarranas. Aunque quizá también podría ser consecuencia directa del programa de construcciones desarrollado por los califas almohades, que habría contribuido a difundir y asentar la práctica edilicia del tapial desde finales del siglo XII. Esta circunstancia podría explicar sus homogéneas características formales, técnicas y constructivas en todo el territorio de al-Andalus. Es por ello, que los restos de estructuras dispersas rurales constituyen un elemento imprescindible para entender no solo la forma constructiva sino también la ordenación territorial de al-Andalus.

\section{LAS TORRES DE TAPIA EN LOS ASENTAMIENTOS RURALES DE AL-ANDALUS}

Según interpretación de los investigadores franceses Bazzana, Guichard y Cressier, el hiṣn o castillo rural surge a partir de las comunidades campesinas y es un nodo importante dentro de la organización territorial andalusí. El hiṣ̣n se ubicaría en un emplazamiento más o menos inaccesible y tendría un uso temporal como habitat y refugio en caso de peligro. Cada castillo estaría asociado a varios núcleos de asentamientos rurales como las qurà o alquerías que, a su vez, estarían relacionadas estrechamente con la red hídrica y por tanto estarían situadas en emplazamientos más bajos. Este sistema de elementos articularían un distrito o circunscripción de orden inferior a la cora que vendría a ser denominado iqlìm (pl. aqālìm), clave en la ordenación del territorio islámico junto a las ciudades (Acién 2008: 153). La naturaleza de estos distritos de tamaño inferior no esta suficientemente aclarada, ni tampoco su relación con otras unidades administrativas denominadas 'amal o amelía, aparentemente circunscripciones de mayor entidad que los aqālìm pero menores que las coras. Algunos autores andalusíes en las descripciones de su linaje citan hasta cuatro niveles administrativos: la qarīa o unidad básica de poblamiento, el iq $\mathbf{i} m$ o distrito, el 'amal o amelía y la cora o provincia (García San Juan 2017: 156).

En época omeya, la alquería o al-qarīa era la primera unidad para el establecimiento de impuestos (Barceló 1984). La alquería constituiría la principal tipología habitacional destinada a la explotación de los recursos agropecuarios y sería uno de los hábitats rurales de primer orden. Como unidad de poblamiento la qarīa era uno de los primeros escalones de la jerarquización territorial y administrativa islámica. Sería una entidad diferente a los barrios (hara) ya que estos formarían parte de la misma ciudad y la alquería o aldea estaría al servicio de la ciudad (Acién 2008: 148). Guichard establece que la alquería era una zona rural con el asentamiento sedentario de una comunidad. Una colectividad solidaria en los derechos que ejercían sobre las tierras cercanas sus propietarios, habitantes de esos asentamientos (Guichard 1988). Estos pequeños núcleos de población estaban compuestos por casas agrupadas que, en algunos casos, poseían equipamientos como baños públicos e incluso alguna mezquita. Diversas fuentes hablan de la "gente de las alquerías" o de sus consejos de representantes, ya que eran comunidades que tenían autonomía respecto a la cora, relacionándose directamente con el Estado sin otro tipo de intermediarios ${ }^{12}$.

La alquería no sólo estaba formada por viviendas concentradas en un lugar sino que también tenía asociadas tierras de labor en las que podía haber otros asentamientos más pequeños como las cortijadas (maŷāšir) o las granjas ( $r a h \bar{a} l)$, entidades de orden menor, en general, pertenecientes a un sólo propietario (Guichard 1988: 164). De manera que la alquería era un poblamiento complejo compuesto por inmuebles agrupados y/o dispersos con vinculos comunes que gestionaban un territorio propio con cultivos y terrenos irrigados. Patrice Cressier en sus estudios sobre la Alpujarra mantiene que, a veces, había pequeños núcleos o pedanías separadas aunque pertenecientes a una misma alquería (Cressier 1987: 181, 1991: 412). Aparte de las tierras destinadas a cultivos, las alquerías también disponían de

\footnotetext{
12 Hecho que queda de manifiesto en la rendición de alguna alquería a los castellanos, en un momento tan tardío como la guerra de Granada (14821491), que estuvo negociada por un alfaquí escogido por toda la comunidad y no por un alcaide o representante del poder nazarí.
} 
pastos y monte de aprovechamiento comunal (harim) o tierras "muertas" (mawat) por encima del terreno irrigado (Acién 2008: 150).

La mayoría de esos pequeños núcleos surgen con el fin de obtener aprovechamientos agropecuarios, tenían presencia de ganadería en algunos lugares y estaban orientados al abastecimiento del mundo urbano de las mudun o ciudades, por lo que se encontraban integrados en redes comerciales, es decir, también se relacionaban con el sistema de infraestructura compuesto por caminos y vías pecuarias. Estos poblamientos que colonizaban valles y llanos aparecen junto a tierras fértiles destinadas a agricultura irrigada, zonas de vega en llanuras aluviales o bien en laderas suaves donde disponer cultivos abancalados. Normalmente, se sitúan en altozanos, lugares que actuarían como centralizadores de asentamientos por el lógico interés de las comunidades campesinas de agruparse para proteger sus recursos y patrimonios de arriadas, inundaciones $u$ otros factores ambientales imprevisibles.

Los asentamientos poblacionales constituían pues un sistema de nodos, a escala diferente de los husūn, con capacidad para organizar comarcas, antropizar espacios o controlar las cercanas tierras cultivadas. Tanto las qurà como los husūn construían una articulada red distribuida en el territorio pero ambos con fines y usos diversos. Sus promotores y constructores debieron ser las comunidades rurales aunque, indudablemente, con conocimiento del Estado que aprovecharía estas eficaces implantaciones y sería el primer beneficiado, trámite impuestos, de este sistema de ordenación del territorio (Acién 2008: 159). Existe constancia de asentamientos rurales musulmanes de alquerías en Alcaria Longa (Mértola) y Alcaiais de Odeleita (Castro Marim, Faro) en Portugal; La Mesa en Chiclana de la Frontera (Cádiz), El Castillejo de Los Guajáres (Granada), Beniham (Castellón), entre otros lugares (Pérez Aguilar 2013).

Estos núcleos rurales de casas, a veces, también podían contar con una torre a la que se asociaba un recinto o albacar que, en caso de rapiñas o incursiones esporádicas, sería un refugio para el ganado y la población de la alquería más cercano que el hisn asociado a la misma. Es posible que, en momentos tardíos del dominio almohade debido a la amenaza de los reinos cristianos y a la movilidad de la franja fronteriza, el sistema productivo de alquerías fuera intervenido progresivamente por el Estado para construir esas torres con objeto de dedicarlas a un control territorial, fiscal o militar. Algunos testimonios cristianos del momento de la conquista describen estas estructuras fortificadas con viviendas, refiriéndose a ellas como castrum et alqueriam (López Elum 1994: 44-53). Por otro lado, en lugares llanos como el entorno valenciano o la campiña cordobesa, la capacidad de alerta de una alquería o población se vería complementada e incrementada al dotarse con una torre.

Las torres no aparecían en todas las alquerías pero es posible pensar que cuando esta estructura en altura se presenta haya habido algún tipo de asentamientos rural importante (Pérez Aguilar 2013). Hay constancia de alquerías con torre en Nigüelas (Granada), los Álamos y Torre de la Horra (San Roque), en la Alpujarra almeriense en Alhabía (Alcudia de Moteagud), Benimina (Benizalón), Medala y Benalguaciles (Cressier 1987: 182) entre otros lugares. Todos ellos son núcleos lejanos a la frontera con los reinos cristianos, incluso en época nazarí (Fig. 6). Por lo que también es factible pensar que estas construcciones en altura tuviesen otras funciones que trascendieran su posible uso defensivo. Por ejemplo, alzarse sobre los tejados de las casas, lo que permitiría una mejor comunicación entre núcleos vecinos, serviría para el control y vigilancia de cultivos cercanos o como silo para el almacenamiento de productos agrícolas. Estas dos últimas utilidades están prescritas para las casas de labor por Ibn Luyūn en su tratado de Agricultura' ${ }^{13}$.

Estas construcciones rurales proliferaron en zonas productivas de garb al-Andalus, generalmente, en el valle del río Guadalquivir (alrededores de Sevilla, Córdoba y Jaén) y también en šharq al-Andalus en las tierras llanas de Albacete o en las huertas valencianas (entornos de Alcoy, Alcira, Játiva, Denia). Hay constancia de este sistema de torres y alquerías por la crónica del monarca Jaime I durante la conquista de Valencia en 1238 (López Elum 1994: 49-50). En torno a esta ciudad existía gran número de alquerías con torre. Un grupo de ellas se encuentra a unos $6-8 \mathrm{~km}$ al oeste de la ciudad de Valencia y otro grupo más lejano a unos $13 \mathrm{~km}$ al norte y sur (López Elum 2002: 32). Sin embargo, no está claro si su distribución surgió por motivos defensivos o productivos.

En la Sierra Calderona, la cuenca del Turia y la albufera valenciana subsiste un importante número de torres asociadas a alquerías. Uno de los casos más documentados y estudiados es la torre de Bofilla en Bétera en la provincia de Valencia (Mileto et al. 2011).

\footnotetext{
13 Ibn Luyūn indica que el emplazamiento de una casa de labor se debe elegir en un altozano que facilite su guarda y vigilancia y que es fundamental que las alquerías y casas de labranza tengan un silo para el estiércol situado de forma que no produzca molestias (Eguaras 2014: 272-274).
} 


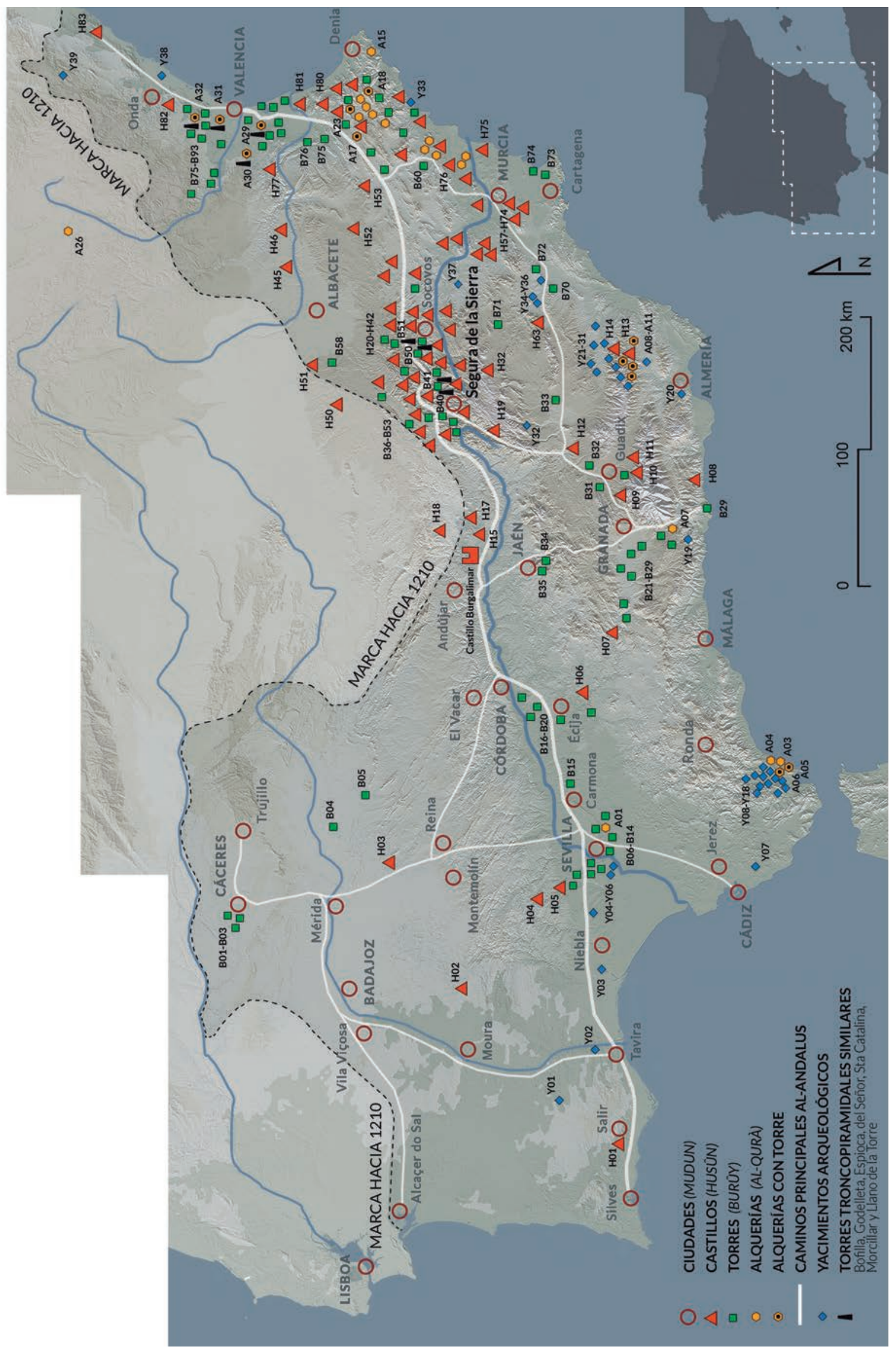




\section{GARB AL-ANDALUS}

\section{Alentejo y Algarve}

H01. Castillo de Paderne $*$,
Y01. Alcaria Longa (Mértola)

Y01. Alcaria Longa (Mértola)
Y02. Alcariais de Odeleite (Castro Marim)

Via de la Plata y cuenca del Guadiana
H03. Castillo de Hornachos
B01. Torre Redonda (Cáceres)
B02. Torre Desmochada (Cáceres)
B03. Torre de los Pozos (Cáceres)
B04. Torre de Magacela
B05. Torre de Benquerencia de la Serena *

Aljarafe, Alcores, valle del Guadalquivir y campiña
cordobesa

Y03. Los Parrales (San Juan del Puerto)

Y04. Purchena y Los Cascos (Chucena)

H04. Castillo de las Guardas

H05. Castillo de Luna (Mairena del Alcor)

B06. Torre de la Dehesilla (Aznalcóllar)
B07. Torre de San Antonio (Olivares)

07. Torre de San Antonio (Olivares)
08. Torre Mocha de Don Fadrique (Albaida Aljarafe)

8. Torre Mocha de Don Fadrique
Torre de Loreto (Espartinas)

Y06. Los Olivos, EI Cruce. Los Eucaliptos (La Puebla del Rio)

11. Torre de la Corchuela (Dos Hermanas)

2. Torres del Palacio de Aznalfarache *

3. Torre Blanca

Torre del Gandul

Torre Huerta Martín Pérez

Torre de Gallape (

6. Castillo de Alhonoz (Écija)

9. Torre de Diezma Ayusa

B20. Torre de Albaén

\section{Sistema penibetico}

Y07. La Mesa (Chiclana de la Frontera)
Y08. El Chorrito (Castellar de la Frontera)

Y10. El Ermitaño (Castellar de la Frontera)

11. Corral de las Vacas (Castellar de la Frontera)

112. Matillas (Castellar de la Frontera)

113. Loma de Hato Alto

Y15. Cortijo Barría (Castellar de la Frontera)

15. Cortijo Barría (Castellar de la Frontera)

Y17. Huerta de Santa Clara
Y18. Cortijo Garranchal

A02. Granados

A03. Patraina

A04. Tábanos
A05. Los Álamos (San Roque)

A06. Torre de la Horra (San Roque)

07. Castillo de Turrush (Algarinejo)

21. Torre el Frontil

Torre de Huétor Tájar

Torre de Cijuela

Torre de Las Gabias
Torre de Alhendin

Torre del tío Bayo (Albuñuelas)

El Castillejo (Los Guájares)

Torre de Marchena (Dúrcal)

Torre de Alquería Nigũelas

Torreón del Ferro (Castel de Ferro)

8. Castillo de la Rábita

09. Castillo de la Pera

410. Castillo del Barrio (Lanteira)

11. Castillo de Ferreira

Torre Paulenca (Guadix)

2. Torre de Magrú (Purullena)

H12. Castillo de B

333. Torre del Alabi (Cúllar)
Y21. Sufli

Y22. Cuesta Roca

Y23. Torre Negra, el Moratón y los Perales

Y25. Benitorafe

Y26. Torre de los Casarazos.

H13. Castillico de Benizalón

A11. Benimina (Benizalón)

H14. Castillico de Benitagla (Almería)

Y28. Albánchez

Y29. La Hoya

Y30. La Torrecica
Y02. Alcariais de Odeleite (Castro Mari
H02. Castillo de Noudar (Barrancos)

Y05. La dehesa de Puñana (La Puebla del Rio)

B10. Torre de los Herberos (Dos Hermanas)

1. Torre Alquería de Quintos

8. Torre de Don Lucas (La Victoria)

Y09. Dehesa de Cotilla (Castellar de la Frontera)

8. Tahal (Alcudia de Monteagud)

A09. Medala (Alcudia de Monteagud)

127. Llano de la Lámpara (Purchena)

\section{SHARQAL-ANDALUS}

B34. Torre Bermeja Peñas de Castro *

B35. Torre de Pedro Codes

H16. BURGALIMAR (Baños de la Encina)

H17. Castillo de Giribaile (Vilches)

H18. Castillo de las Navas de Tolosa

\section{Sierra de Segura}

Y32. Los Hiniestares, Cebas y Lezas.

H19. Castellón del Moro (Segura de la Sierra)

H20. Castillo de Hornos de Segura

B36. Torre Altamira (Segura de la Sierra)

B37. Torre de Gutamarta (Segura de la Sierra)

H21. Castillo de la Espinareda

H22. Castillo de Peñolite (Puente Génave)

H23. Castillo de Bujalamé (La Puerta de Segura)

24. El Castillo (La Puerta de Segura)

225. Castillo de Matamoros (Puente Génave)

426. Castillo de Segura de la Sierra

B39. Torre de Góntar (Segura de la Sierra) *

840. Torre Sur de Santa Catalina (Orcera)

342. Torre Baja de Santa Catalina (Orcera)

343. La Torre (Valdemarin)

45. Fuente de La Torre (Benatae)

B46. Torre de la Laguna (Génave)
B47. Torres de Puente-Honda (Siles)

H27. Castillo de Morles (Siles)

H28. Castillo de la Yedra (Torres de Albánchez)

H29. Castillo de Peñafleita (Siles)

H30. Castillo de Tasca (Siles)

H31. Castillo de Miller (Santiago-Pontones)

\section{Cuenca del río Segura}

H32. Castillo de Taibilla (Nerpio)

H33. Castillo de Góntar (Yeste)

H34. Castillico de Góntar (Yeste)

H35. Castillo de la Graya (Yeste)

B48. Torre de Vizcable (Yeste)

H36. Castillo de Yeste (Yeste)
B49. Torre de Moropeche (Yeste)

B49. Torre de Moropeche (Yeste)
H37. Castillo de Iznar (Letur)

B50. Llano de la Torre (Yeste)

351. Torre del Morcillar (Molinicos)

53. Torre de Torre-Pedro (Molinicos)

H38. Castillo de Vegallera (Molinicos)

H39. Castillo de Molinicos

H40. Castillo de Letur (Letur)

H41. Castillo de Socovos
H42. Castillo de Vicorto (Elche de la Sierra)

Cuenca rlo Mundo, río Júcar y Cabriel

B54. Torre de Haches (Bogarra)

H43. Castillo de la Yedra / murallas Ayna

H44. Castillo de Hijar (Liétor)

B55. Torre de Bogarra (Caude

H46. Castillo de Villa de Ves

\section{Tierras de Alcaraz}

H47. Castillo de Cotillas

H48. Castillo de Riópar Viejo

B57. Torre de Lugar Nuevo (Riop

B49. Castillo de Alcaraz (Albacete)

H50. Castillo de San Felices (Ossa de Montiel)

H51. Castillo de Munera

B58. Torre de Lezuza

Corredor de Almansa

H52. Montealegre del Castillo

H53. Castillo de Caudete

Campo de Hellin

B59. Torre de Isso (Hellin

H54. Castillo de Hellin

H55. Castillo de Sierra (Tobarra)

Sistema prebético

A12. Aspe

H57, Castillo del Rio (Alicante)

A13. Monforte del Cid

B60. Torre castillo de La Mola (Novelda) *

H58. Castillo de Busot (Alicante)

B61. Torre de Cabrafich

Y33. Baranyes

H59. Castillo de Aigúes de Busot

62. Torre del Castillo de Tibi

863. Torre del Castillo de la Atalaya (Villena) *
B64. Torremanzanas
44. Torre y recinto EI Cardete (Benatae) *

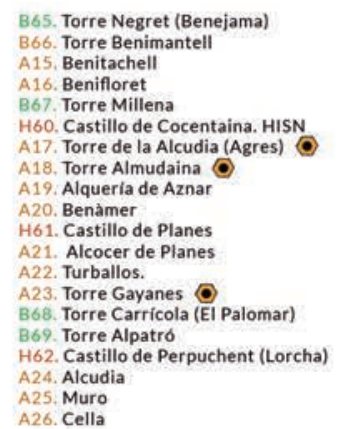

Vegas alta y baja del Segura

H63. Castillo de Xiquena (Lorca)

B70. La Torrecilla (Lorca)

Y34. El Cortijo del Centen

Y35. Puentes (Lorca)

136. Molino de la Venta

871. Torre de Mata (Caravaca de la Cruz)

B72. Torre de Mena (Lorcal

(Murcia)

H55. Castillo de Pliego

Y37. Villla Vieja (Calasparra)

B73. Torre de Oviedo (La Puebla)

B74. Torre del Rame (Los Alćázares)

H67. Castillo de la Asomada (Murcia)

H68. Castillo Portazgo Superior (Murcil

H70. Castillo de Blanca

H71. Castillo de Cieza

472. Castillo de Larache (Murcia)

Segura (Orihuela)

27. Almoradi.

H75. Castillo de Guardamar (Orihuela)

H76. Castillo de Crevillente (Orihuela)

Macizos del Caroig y Monduver

875. Torre de los Borja (Canals)

H77. Castillo de Dos Aguas

Cuenca del Turia y albufera de Valencia

H78. Castillo de Sax

479. Castillo de Carbonera (Beniatjar)

H80. Castillo de Chio (Luchente)

B76. Torre de Antella (Alcira)

H81. Castillo de Corber

B77. Torre de Alfarp

B79. Torre de Muza (Benifaió)

80. Torre de Racef

81. Torre de Montro

29. Torre Espioca (Picassent) O I

82. Torre de Silla

A30. Torre Godelleta 0 ( I

Sierra de las Cabrillas

883. Castillo y Torre de Gestalgar

B84. Torre de Sot de Chera
B85. Torre de

Sierra Calderona

B86. Torre de la Reina Mora

687. Torre de Albal

32. Torre del Señor 1

Torre de Ría (Serra)

1. Torre de Pardines (Olocau)

B93. Torre de Olla (Olocau)

Sierra de Irta

H82. Castillo de Shun (Uxo)

Y38. Beniham (Burriana)

H83. Castillo de Alcalá Xibert *

Y39. Font Voltà

$\begin{array}{cl}\text { HXX } & \text { Castillo (Hisn) } \\ \text { BXX } & \text { Torre (Bury) } \\ \text { AXX } & \text { Alquería (al-qaria) } \\ \text { YXX Yacimiento arqueológico } \\ \text { Torre troncopiramidal similar } \\ \text { - Alquería con torre } \\ \text { * Elementos con revocos y calicostrados } \\ \end{array}$

Figura 6. Distribución de estructuras rurales del siglo XII y XIII en el antiguo territorio de al-Andalus de las que en la actualidad se conserva algún resto. En el mapa se ha representado, además de las ciudades principales, la ubicación aproximada de: ḥusūn o castillos rurales, torres, alquerías, alquerías con torre, yacimientos arqueológicos de alquerías. Fuente: elaboración propia. 
Destacan por sus semejanzas formales y constructivas las torres troncopiramidales del Señor (Serra) o las de Godelleta, Espioca (Picassent), Muza (Benifaió), Raçef (Almussafes). Estas dos últimas construidas con bóvedas y muros diafragma, pertenecen a un tipo más evolucionado que las cuatro primeras (Rodriguez Navarro 2018). En la provincia de Albacete hay numerosos ejemplos de torres construidas en tapial de época islámica, de entre ellas destacan la del Morcillar (Molinicos) y la del Llano de la Torre (Yeste) ambas con forma troncopiramidal y que aún conservan lienzos del recinto o albacar. Son estructuras muy similares en forma y construcción a las torres norte y sur de Sta. Catalina de Orcera en Jaén.

En el territorio del Alto Guadalquivir también se han conservado otros interesantes elementos construidos en tapial. Cabe señalar la torre de Sta. Eufemia en Cástulo (Linares), la torre de las Peñas de Castro o torre Bermeja, situada en una zona con surgencias de agua al sur de la ciudad de Jaén, con un interesante aljibe parcialmente conservado bajo la misma. Estas construcciones tienen en común el empleo del tapial pese a haberse ubicado, normalmente, sobre asentamientos previos con abundancia de piedras y sillares labrados que fueron empleados en algunos casos como cimientos o zócalos.

En el Bajo Guadalquivir se han documentado una serie de torres que podrían atribuirse a época almohade. Algunas de estas construcciones se conservan en la campiña de Córdoba, cerca de La Victoria (Martínez 2005); es el caso de las torres de Don Lucas, Diezma Ayusa o Albaén. Entre las torres desaparecidas se tienen noticias de las de Abentoxi, Beni Moda, Archia, Adalit y Aben Calez (Martínez y Tristell 1998: 56-257; Martínez 2003, 2015). En los alrededores de Dos Hermanas (Sevilla) se conservan algunos restos datados como almohades, como la torre Corchuela y la torre de los Herberos, así como la torre de la alquería de Quintos, esta última construida en el siglo XIII poco antes de la conquista cristiana de Sevilla en 1248 (Valor 2004a: 158). También en la provincia de Sevilla se localiza la torre de la Huerta de Martín Pérez en Carmona. En el al-Sharaf (Aljarafe) los ejemplares conservados que se pueden fechar en época almohade son la torre de San Antonio (Olivares), conquistada en 1248 por las tropas cristianas de Fernando III (Valor 2004a: 146), y la torre de Don Fadrique o torre Mocha (Albaida del Aljarafe).

A partir del siglo XIV, durante el reino nazarí, el uso del tapial comenzó a ser sustituido por la mampostería enripiada con sillares en las esquinas, por lo que una gran parte de las torres que se han conservado de esa última etapa islámica no son de tapial. El cambio de material permitió que las torres comenzaran a abandonar la planta cuadrangular por la circular para evitar también los daños derivados del uso creciente de la artillería, viéndose influenciadas por las construcciones militares cristianas desarrolladas en zonas fronterizas. A pesar de ello, en la vega de Granada se construyeron algunas torres en tapial calicostrado de las que se conservan algunos ejemplos como las torres de Huétor Tájar, Las Gabias, Alhendín o Cijuela. De todas ellas, por su singularidad, destaca la torre de Romilla en Chauchina.

\section{LAS TORRES DEL VALLE DE LOS RÍOS GUADALIMAR, HORNOS Y TRUJALA}

La ocupación del valle así como su evolución en época medieval ha sido ampliamente estudiada (Salvatierra et al. 2006). Esta comarca debió permanecer sustancialmente deshabitada antes del siglo X. Hasta ese momento el núcleo de Segura de la Sierra es citado solo como hiṣn por Ibn Sa'īd y Abū-l-Fidā' (Salvatierra y Visedo 2008). Al inicio de época islámica, los principales puntos de ocupación de esta comarca fueron las cotas más altas de las montañas, donde se situaron los principales h̆usūn como Hornos (894 m.s.n.m.) o Segura de la Sierra (1220 m.s.n.m.). Castillos que tenían como principal función el control de acceso al interior de las sierras que era donde estaban los principales recursos productivos de los núcleos poblacionales (Salvatierra y Visedo 2008: 149). La parte baja del valle comienza a ser colonizada a partir del siglo citado, quizás como consecuencia de la política de bajada al llano impuesta por Abd al-Rahmān III, siendo definitivamente poblada durante el siglo XI cuando se produjo una intensificación agrícola en toda la comarca.

En el siglo XII, el geográfo musulman Muhammad al-Idrīs $\overline{1}^{14}$ ubica Šaqura en una zona montañosa situada entre el «garb» y el «šark» de al-Andalus. Indica que es un lugar de donde parte, hacia la vega de Mursiyya,

\footnotetext{
14 Abū Abd Allāh Muhammad al-Idrīsī, geógrafo, cartógrafo y viajero ceutí que, hacia el año 1154, dibuja un mapamundi para el Kitāb Ruyar, dedicado al rey normando de Sicilia Roger II en el que ubica la localidad de Šaqura. La importancia de Segura fue tal que su localización quedó reflejada en otras cartografías como el Mapa Mundi de Abraham y Yehuda Cresque conservado en la Biblioteca Nacional de París.
} 
un curso fluvial llamado al nahr al abiad (río Segura), cercano al cual nacen también al nahr al Safam (río Guadalquivir) y al nahr tania (río Guadalimar) (Fig. 7). Al-Zuhrīun ${ }^{15}$, geográfo que trabajó en la corte almohade a mediados del siglo XII, afirmaba que la Sierra de Segura era una región densamente poblada, tratándose de una zona montañosa fértil, donde las cosechas, el ganado y los frutos se producían en abundancia. Indica además la existencia de unas trescientas qurà, diversos refugios de altura (ma'qil) y treinta y tres hușûn (Guichard 1990: 58). La conexión entre $\dot{g}$ arb al-Andalus y šharq al-Andalus se realizaba en el valle de los ríos Guadalimar y Hornos donde confluía el camino del Arrecife que venía desde Córdoba y Sevilla con el camino Collado de las Almendros que provenía de Granada, ambos se unían cerca del actual núcleo de La Puerta de Segura partiendo hacia Levante como una única vía llamada camino de los Cartagineses (Ballesteros 2000) (Fig. 8).

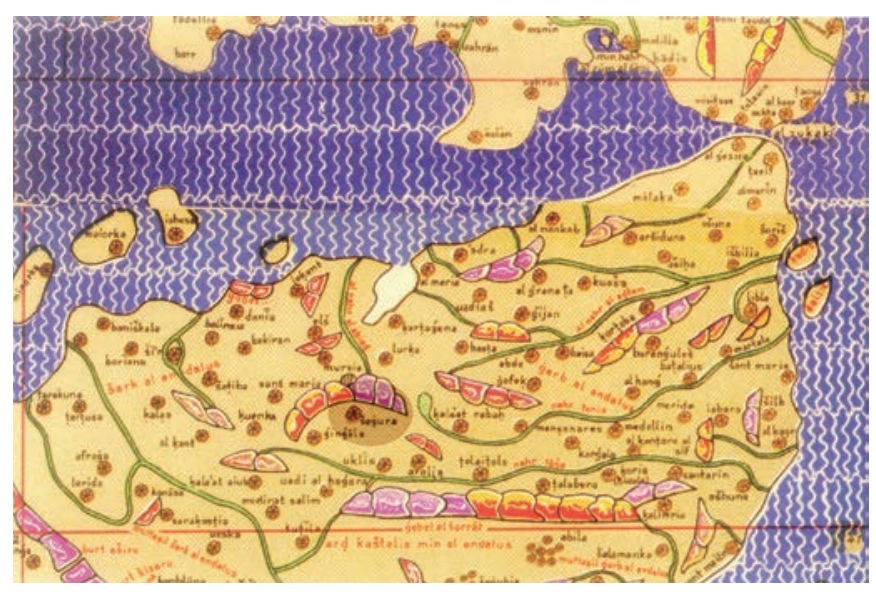

Figura 7. Ubicación de Šaqura en al-Andalus, representado en la cartografía del mundo realizada por Abū Abd Allāh Muhammad al-Idrīsī en 1154 para el Kitāb Ruyar y dedicado a Roger II, rey normando de Sicilia (clima IV, sección 1). Este dibujo se trata de una interpretación del original realizada por Konrad Miller, Stuttgart 1928. Fuente: Library of the Congress, Washington.

\footnotetext{
15 Mohammed Ibn Abi Bakr al-Zuhrī fue un geográfo andalusí de Granada, autor de Kitāb al-Jaghrafiyya (Libro de Geografía). Trabajó en la corte del primer califa almohade Abd al-Mu'min, y murió en torno al año 1161.
}

Šaqura era una circunscripción administrativa o 'amal, inicialmente perteneciente a la cora de Yayyan, que se acabó convirtiendo en una taifa independiente. El territorio de la taifa de Šaqura fue gobernado desde 1147 y durante casi treinta años por los señores locales Ibn Hamušk y su yerno Ibn Mardanīš (Cruz 1994) ${ }^{16}$. Un periodo en el que, junto con el resto de šharq alAndalus, fue autónomo del Estado almohade con capital en Sevilla (Navarro y Jiménez 2012: 291-294). En este territorio segureño y sobre el río Trujala se construyó un embalse de agua, una infraestructura hidráulica destinada a irrigar las zonas cultivables de los Llanos de Sta. Catalina. De la presa de tapial que contenía el agua del pantano aún se conserva, en el actual paraje denominado Garganta del Ciervo, gran parte del estribo lateral izquierdo y algunos restos del arranque (Salvatierra y Gómez 2016). La imagen de la lámina de agua del embalse aún pervive en la toponímia del lugar con el nombre de Albuhera, que es como se conoce un pequeño arroyo que discurre por ese paraje.

La conquista de este territorio por los cristianos y su posterior entrega a la Orden de Santiago está suficientemente documentada por varias crónicas del momento (Caparrós 2011: 227-228). Más adelante, comienzan a aparecer relatos con descripciones de los elementos existentes en la zona como las relaciones de Francisco de León de 1468 que describen la existencia de torres, algunas hoy desaparecidas como las que había en Orcera o Catena (Eslava 1989: 374). Por las Relaciones Topográficas de Pueblos, encargadas por Felipe II en 1575, también se tienen noticias de otras torres perdidas como las de Bujalame, Benatae o Morles (Villegas y García 1976: 113-231).

\footnotetext{
16 Ibrahim Ibn Hamušk fue un muridin que se rebeló en 1144 en Socovos y tres años más tarde se convirtió en señor de Segura de la Sierra. Poco después, en 1147, su yerno Ibn Mardanīš tomó el poder en el territorio de Valencia y, más tarde, en el de Murcia convirtiéndola en su capital. Ibrahim Ibn Hamušk cedió el distrito de Segura de la Sierra a su pariente y entre ambos gobernaron esta importante taifa (1144-1172). Ibn Hamušk saqueó la región de Córdoba, arrebatando temporalmente Écija y Carmona a los almohades, llevando la guerra casi a las puertas de Sevilla. En 1162, se apoderó de la ciudad de Granada. A partir de ese año, los almohades enviaron nuevas tropas desde Marrakesh, obligando a retroceder a Ibn Hamušk que, en el año 1169 , adopta la doctrina unitaria y traiciona a su yerno. En 1172 muere Ibn Mardanīš, los almohades toman Murcia y mantienen como gobernador de la ciudad a su hijo Hilal que se declaró vasallo suyo.
} 


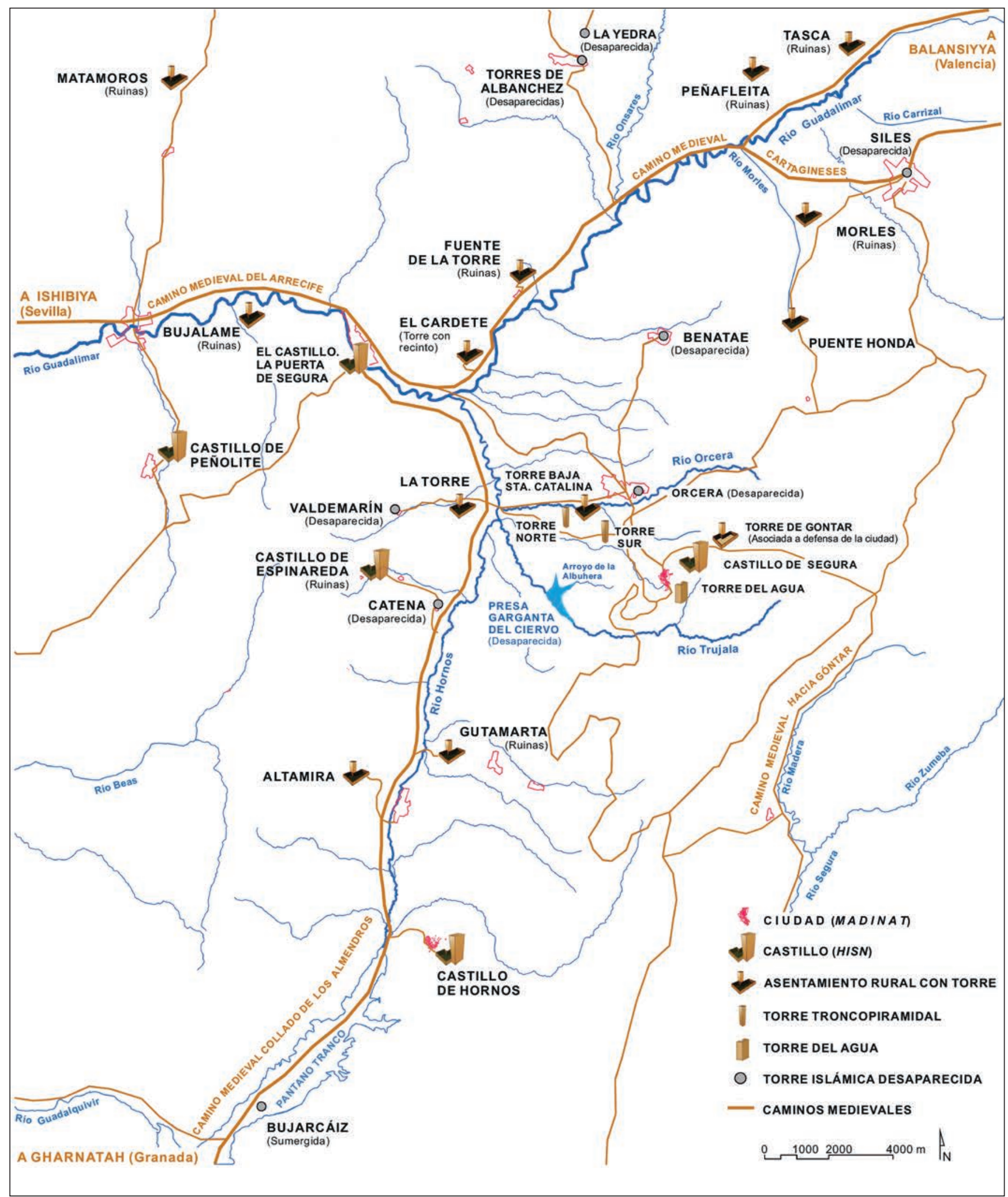

Figura 8. La ciudad de Šaqura y el sistema de husūn, torres, asentamientos rurales, vías de comunicación, cursos fluviales e infraestructura hidráulica del valle de los ríos Guadalimar, Hornos y Trujala en la Sierra de Segura (Jaén). Fuente: elaboración propia. 
A pesar de las torres desaparecidas, todavía subsiste hoy en día un importante conjunto de estructuras en tapial que han sido caracterizadas y descritas, desde el punto de vista constructivo y análisis de materiales, en diferentes proyectos de consolidacion y artículos (Quesada-García y García-Pulido 2015a, 2015b). Todas estas construcciones, relacionadas en la tabla 1, tienen diversas formas consecuencia de los diferentes usos a los que debieron estar dedicadas.

En las partes altas de algunos destacados cerros del valle hay restos de estructuras con varias torres o con vestigios de recintos murarios. Son preexistencias más propias de husūn que torres aisladas vinculadas a asentamientos agrarios. Es el caso de Peñolite o La Espinareda, que serían lo que Manuel Acién denomina como husūn de distritos, es decir, fortificaciones construidas por las comunidades rurales para su refugio (Acién 2008: 159-160) (Fig. 10).

En torno al núcleo de Segura de la Sierra, además del recinto amurallado de la ciudad en pésimo estado de conservación, también hay diferentes tipos de construcciones en tapial muy interesantes y vinculadas a la protección de recursos como el abastecimiento de agua o la defensa de caminos. Este último es el caso de la torre de Góntar o de las Eras que habría funcionado como estructura fortificada adelantada del recinto urbano para defender el acceso del camino que iba hacia Góntar, núcleo en la actual provincia de Albacete. La función de esta torre fue claramente militar o defensiva, como demuestran las numerosas saeteras dispuestas en cada uno de los niveles de sus caras, todas ellas orientadas además hacia el lugar a batir o proteger (Fig. 11).

Un tipo muy interesante y enigmático de estructura es la denominada torre del Agua. Es una construcción en forma de $\mathrm{U}$ adosada a la roca de la montaña, sin ninguna saetera, hueco o acceso y a la que no entesta ningún lienzo de muralla. Esta circunstancia ha llevado a proponer, desde el siglo XVI, que se trata de una torre que protegía una fuente o pozo, de ahí proviene la etimología de su nombre. Sería pues una construcción sin entrada a la que se accedería sólo desde arriba, a través de una presunta escalera tallada en la roca que descendería desde la cima del castillo. Posibilidad bastante inverosimil a la vista de lo escarpado de la roca de la montaña, que es vertical justo en ese punto, además de no tener ninguna lógica funcional, ni desde el punto de vista defensivo, ni del transporte o suministro del agua. Analizando la altimetría de la torre (1157 m.s.n.m.) en relación a la ciudad (1145 m.s.n.m.), el espesor y sección de sus muros, la forma de su construcción, la carencia de accesos o huecos y el trazado de las murallas de la ciudad se plantea aquí la hipótesis, que deberá ser

\begin{tabular}{|l|l|c|c|}
\hline Denominación & Localización & $\begin{array}{c}\text { Altitud } \\
\text { (m s. n. m.) }\end{array}$ & $\begin{array}{c}\text { Coordenadas } \\
\text { UTM X - Y }\end{array}$ \\
\hline El Castillo & La Puerta de Segura & 579 & $522948-4244591$ \\
\hline Torre y albacar El Cardete & Benatae & 634 & $525713-4244279$ \\
\hline La Torre (de Valdemarín) & Orcera & 679 & $525341-4240788$ \\
\hline Torres del castillo de Peñolite & Puente Génave & 692 & $518120-4242113$ \\
\hline Torre Baja de Sta Catalina & Orcera & 727 & $528568-4240619$ \\
\hline Fuente de la Torre & Benatae & 750 & $526835-4246639$ \\
\hline Torre Norte de Sta Catalina & Orcera & 757 & $528582-4240224$ \\
\hline Torre de Gutamarta (Los castillejos) & Segura de la Sierra & 785 & $525157-4234597$ \\
\hline Torre Sur de Sta Catalina & Orcera & 827 & $528985-4239924$ \\
\hline Torre de Altamira & Segura de la Sierra & 973 & $522629-4234011$ \\
\hline Castillo de la Espinareda & Segura de la Sierra & 1134 & $523111-4239321$ \\
\hline Torre y recinto de Góntar & Segura de la Sierra & 1157 & $530811-4239216$ \\
\hline Torre del Agua & Segura de la Sierra & $530706-4239043$ \\
\hline
\end{tabular}

Tabla 1. Elementos de arquitectura en tapial analizados en la Sierra de Segura, ordenadas por su altimetría 

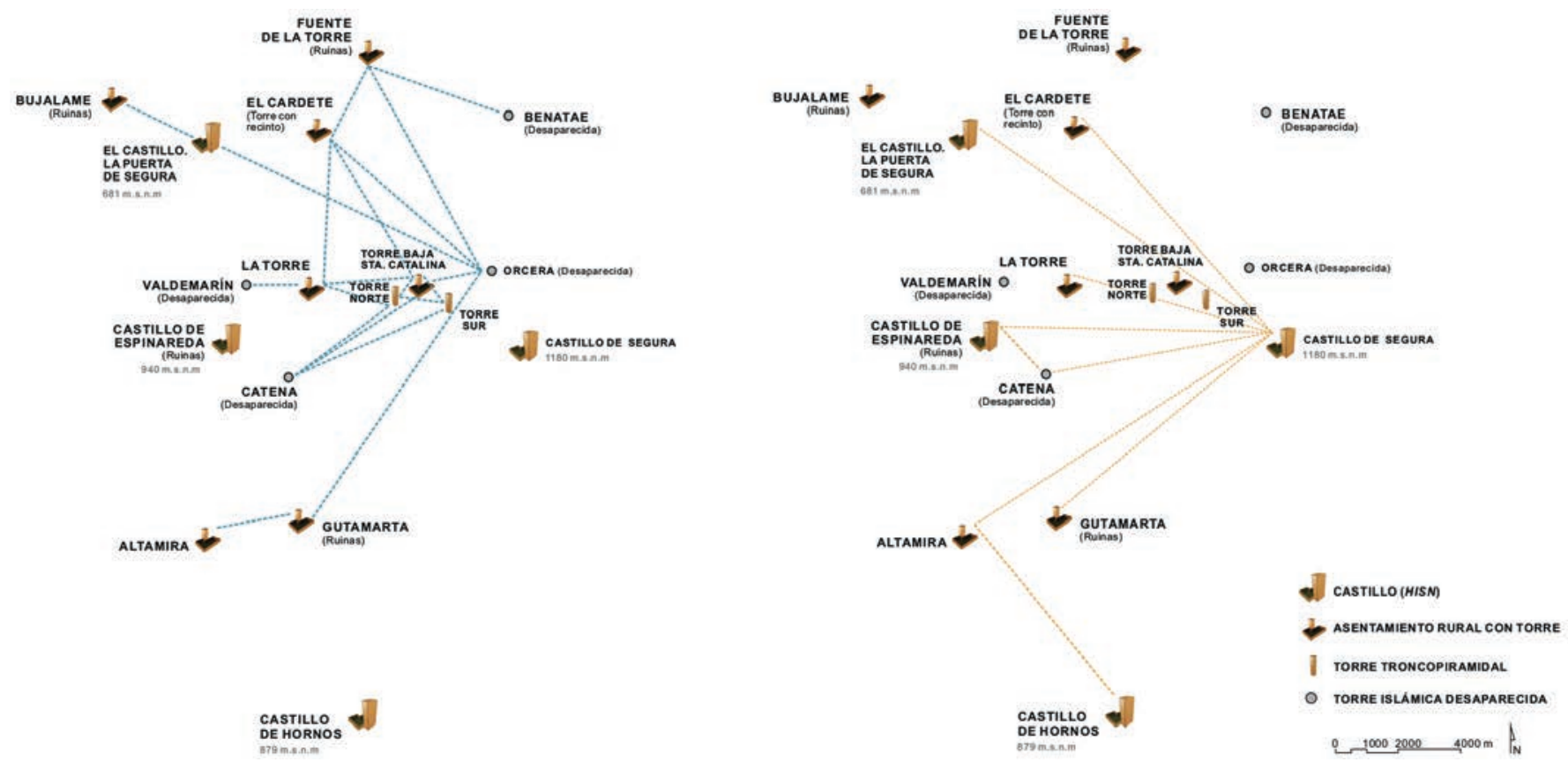

Figura 9. A la izquierda red triangular de relaciones visuales y comunicación entre torres ubicadas en cotas bajas del valle. A la derecha principales visuales entre los husūn ubicados en las coronaciones de las montañes y cerros del valle. Fuente: elaboración propia.
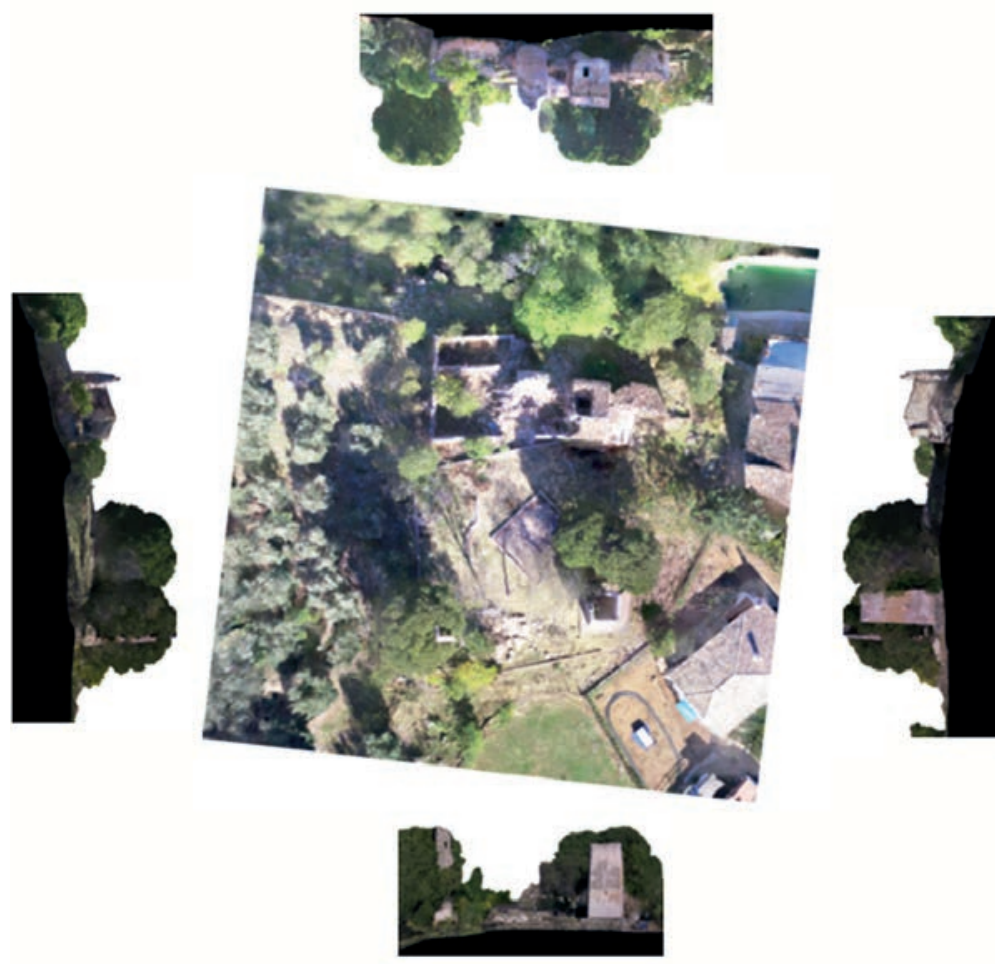


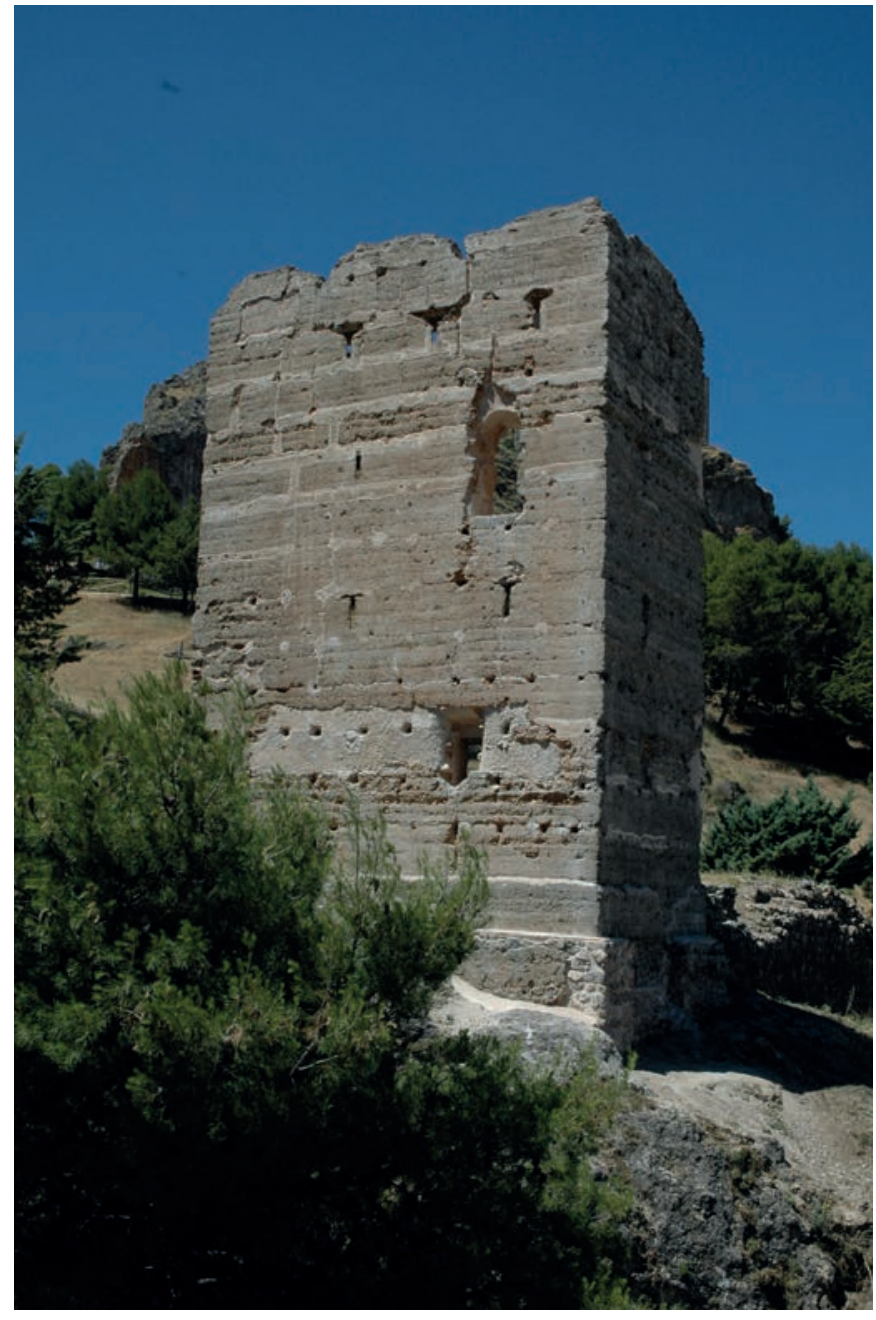

Figura 11. Torre de Góntar (Segura de la Sierra) tras su restauración en 2009. Es la única torre del sistema cuya función era exclusivamente defensiva, tal y como demuestran las numerosas saeteras dispuestas en todos los niveles de la torre; todas ellas orientadas para batir la zona a proteger que era el camino que llegaba a Segura de la Sierra desde la población de Góntar. El hueco con el medio punto es una apertura realizada a posteriori de la construcción original. Fuente: autor.

demostrada en investigaciones futuras, de que este elemento adosado a la montaña, más que una torre protectora o defensiva, era un depósito de agua que abastecía al núcleo de Segura. Si disponían de tecnología para ejecutar una presa en tapial para un embalse, también tenían capacidad para construir depósitos de agua con la misma técnica (Fig. 12).

En la parte baja del valle es donde aparecen la mayoría de las torres diseminadas, aisladas en mitad del campo o integradas en aldeas o caseríos. La implantación de las torres triangula el territorio en las cotas inferiores del valle, evitando ángulos muertos y puntos

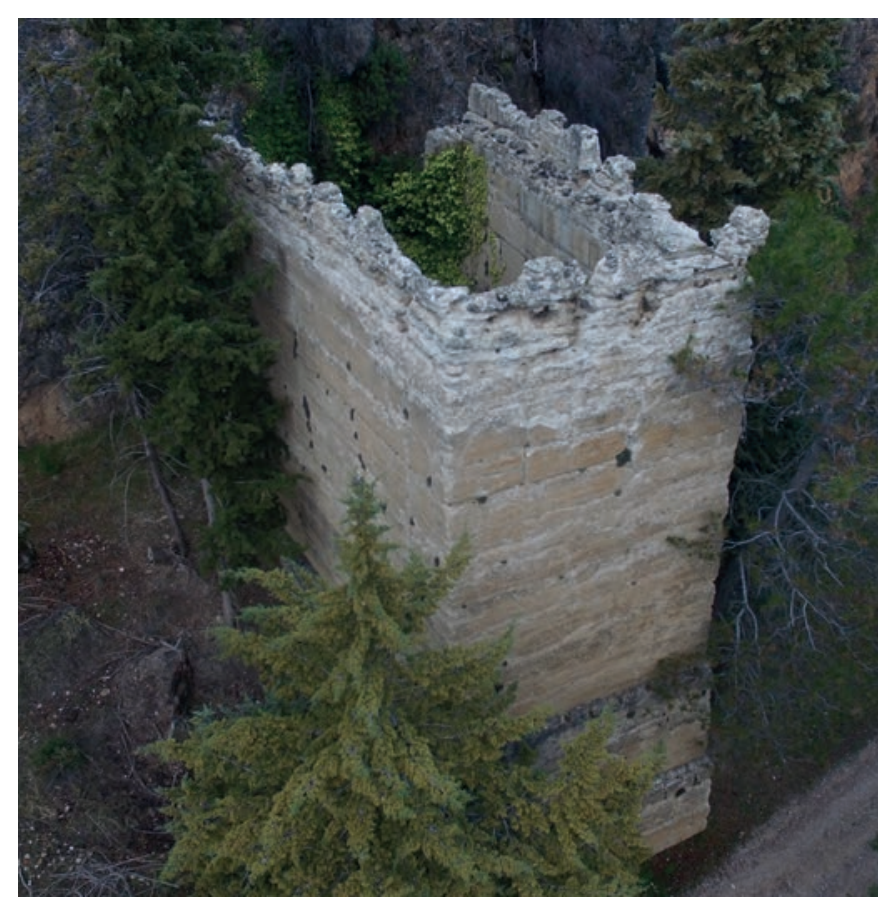

Fig. 12. Torre del Agua (Segura de la Sierra). Se trata de una estructura en forma de $U$ adosada a la roca que no disponía de ninguna saetera, apertura o acceso al interior. La hipótesis que mantenemos es que esta construcción podía haber servido como depósito o regulación de agua para el abastecimiento de la ciudad a partir de algún manantial o surgente.

ciegos, creando una intrincada red de conexiones visuales entre sí y con el terreno circundante cercano. Si el control estratégico de todo el territorio del valle estaba confiado a los husūn de las cotas superiores, cabe pensar que esta red inferior de torres tenía otras funciones diferentes a las estrictamente militares, como podían ser la comunicación entre núcleos poblacionales o atender necesidades agrícolas de asentamientos rurales (Fig. 9).

Cerca del río Guadalimar, sobresale una estructura denominada como El Cardete (Benatae). Se trata del único elemento del valle que junto con la torre conserva aún el recinto asociado a ella. Esto ha permitido conocer 
su trazado y superficie $\left(452,29 \mathrm{~m}^{2}\right)$ (Quesada-García et al. 2017). Es una estructura que se localiza en una elevación a mitad de altura de un monte junto al antiguo camino de los Cartagineses que llevaba a Levante (Fig. 13). La torre mantiene el calicostrado de la fachada sur de la torre prácticamente intacto y en los tapiales de la muralla perimetral del recinto se conservan restos de calicostrado con grafías. Por otro lado, a diferencia de la torre de Góntar, que tiene numerosas saeteras en todos los niveles, la torre del Cardete sólo tiene una por cara, lo que puede ser un indicio de que esta estructura no tuvo un uso estrictamente defensivo (Fig. 14).
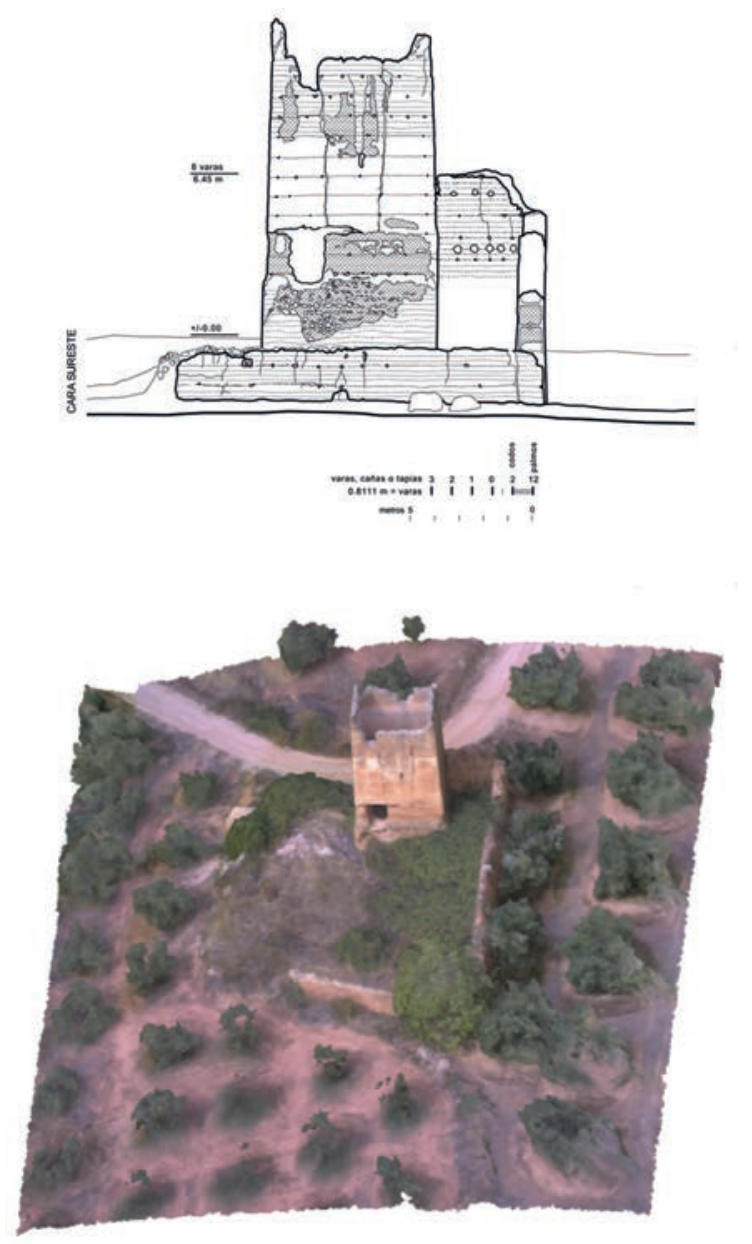

Fig. 13. Torre y recinto El Cardete (Benatae) Es una estructura que se ubica en un altozano a media altura de una colina. El acceso a la torre se encuentra a una cota relativamente baja al estar protegido por el recinto. Es la única torre del valle que conserva todavía el albacar o recinto asociado. Un recinto que está sufriendo un rápido proceso de degradación, ruina y desaparición. Fuente: elaboración propia.
La mayoría de las torres dispersas en las cotas bajas del valle tienen la morfología de una estructura monofásica y monolítica, sin muro diafragma, ni bóvedas en su interior. Son rectangulares y las dimensiones de su planta varían entre 7-8 x 4-5 m. En general, casi todas tienen un acceso relativamente cercano al suelo al estar, probablemente, vinculadas a un recinto amurallado o albacar que las protegía. La altura de sus cajones de tapial está en torno a los $0,75 \mathrm{~m}$, siendo ligeramente diferente en cada torre (con un mínimo de 0,71 m en Fuente de la Torre y un máximo de $0,89 \mathrm{~m}$ en la torre de Altamira), es decir,

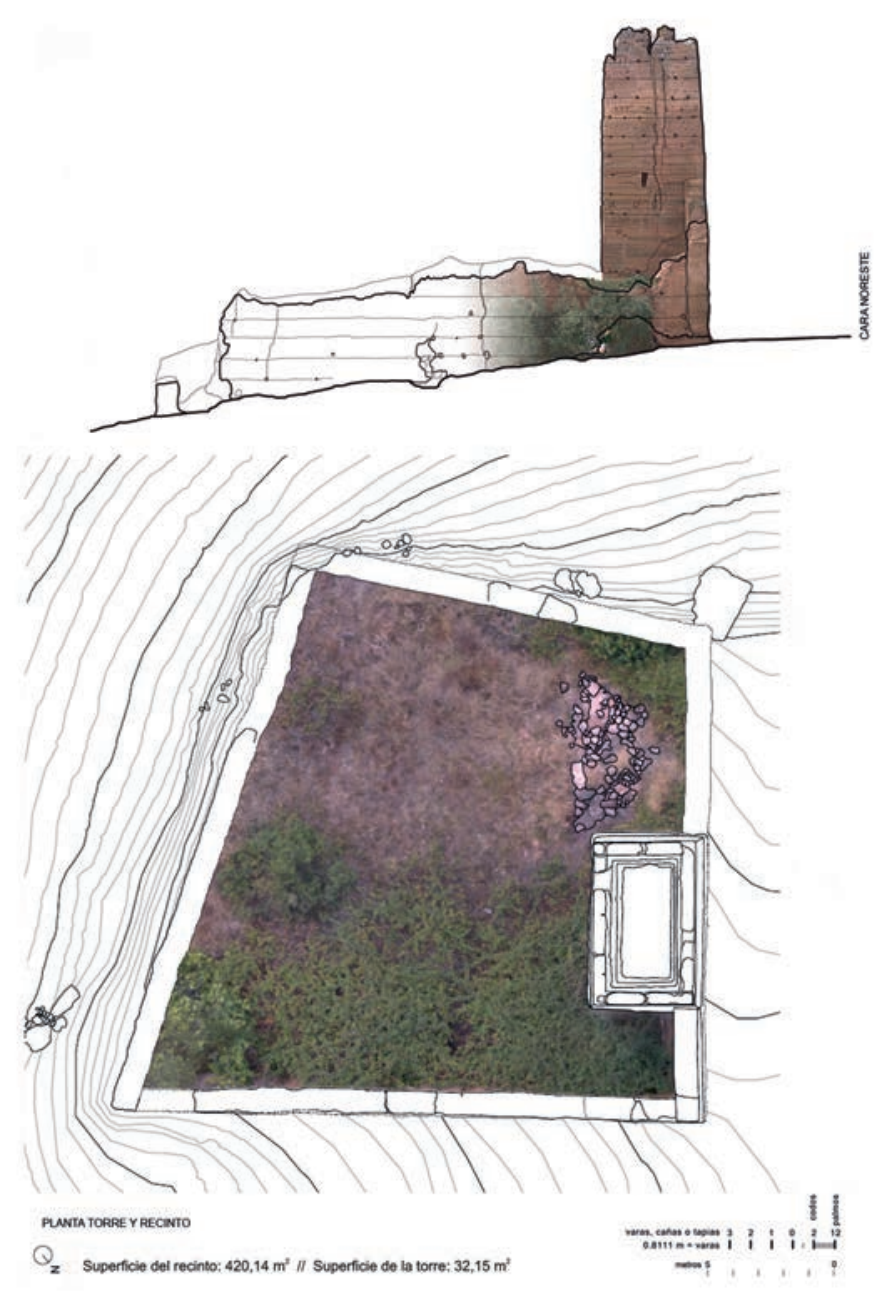

Fig. 14. Levantamiento fotogramétrico y topográfico de El Cardete. Esta torre sólo tiene una saetera por cara, a diferencia de la torre de Góntar. Fuente: elaboración propia. 

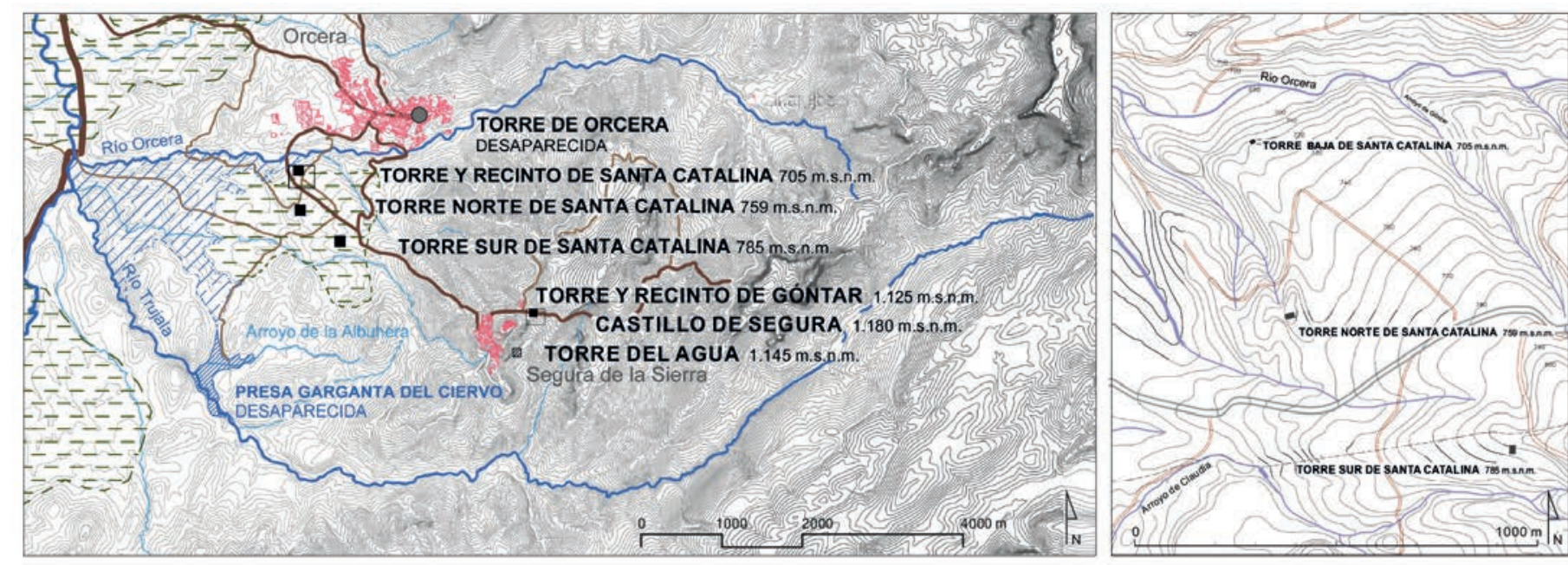

Fig. 15. Llanos de Sta. Catalina (Orcera) con localización e implantación de las tres torres del mismo nombre y de las áreas regables de la zona a partir del agua embalsada en el pantano ubicado en el paraje denominado Garganta del Ciervo (Salvatierra y Gómez 2016). De la presa musulmana original, construida en tapial, aún se conservan restos de los estribos y arranque de la misma. Fuente: elaboración propia.

son cajones de tamaño pequeño (algo menor de dos codos $\left.m a^{\prime} m \bar{u} n \bar{\imath}\right)$. Sus agujas tienen una distribución regular; son pasantes en las zonas bajas de algunas torres y, a partir de una cierta altura, se convierten en medias agujas rectangulares de medida aproximada 7 x $3 \mathrm{~cm}$, situadas a una distancia media de $75 \mathrm{~cm}$. Los dinteles de huecos y saeteras están todos realizados con tableros o rollizos de madera. Las partes bajas de los muros se construyen con hileras de cantos rodados recibidos con un mortero muy rico en cal y grava. Por lo general, los muros están escalonados internamente, comienzan en su parte inferior con una anchura de cajón y medio ( $1,10 \mathrm{~m}$ de ancho) y se reducen progresivamente hasta el espesor de una caja.

En los Llanos de Santa Catalina existen tres torres con igual denominación pero con tipología y forma diferentes (Fig. 15). La torre más ancha y baja, más cercana al núcleo de Orcera, tiene una estructura, dimensiones y forma muy similar al resto de las torres del valle descritas en el párrafo anterior. Las otras dos torres de Sta. Catalina (que hemos denominado norte y sur para diferenciarlas de la primera) son de planta más pequeña que las demás pero también más esbeltas y altas (Fig. 16). Se trata de construcciones monofásicas con forma troncopiramidal, sin muro de diafragma. Ambas torres tienen dos vanos, en caras diferentes, dispuestos al mismo nivel, a una altura considerable del suelo. Son aperturas originales del momento de construcción de los inmuebles como demuestra la disposición de sus dinteles de madera. Debajo de esos huecos, las torres carecen de saeteras o perforaciones (Fig. 17). El acceso a la torre sería la función de uno de esos vanos, el otro no tiene una explicación lógica a no ser que fuera utilizado para la introducción de productos o materiales. Eso indicaría que estas torres pudieron haber sido utilizadas como silo o almacén $\mathrm{u}$ otras funciones como vigilancia de caminos, fiscalización o control de regadíos de la presa Garganta del Ciervo.

\section{PRINCIPALES RESULTADOS Y DISCUSIÓN}

El estudio, análisis e indagación sobre las estructuras medievales de la Sierra de Segura está aportando una serie de datos, algunos de ellos inéditos hasta el momento, así como un conocimiento exhaustivo sobre esta arquitectura islámica construida en tapia en núcleos rurales. Los principales resultados obtenidos son:

- Determinación de los criterios de implantación de las torres localizadas en las cotas bajas del valle de los ríos Trujala, Hornos y Guadalimar. Estas estructuras se colocan relativamente cerca de los ríos anteriores, siempre en la ladera de una colina, sobre un ligero altozano, nunca en la 


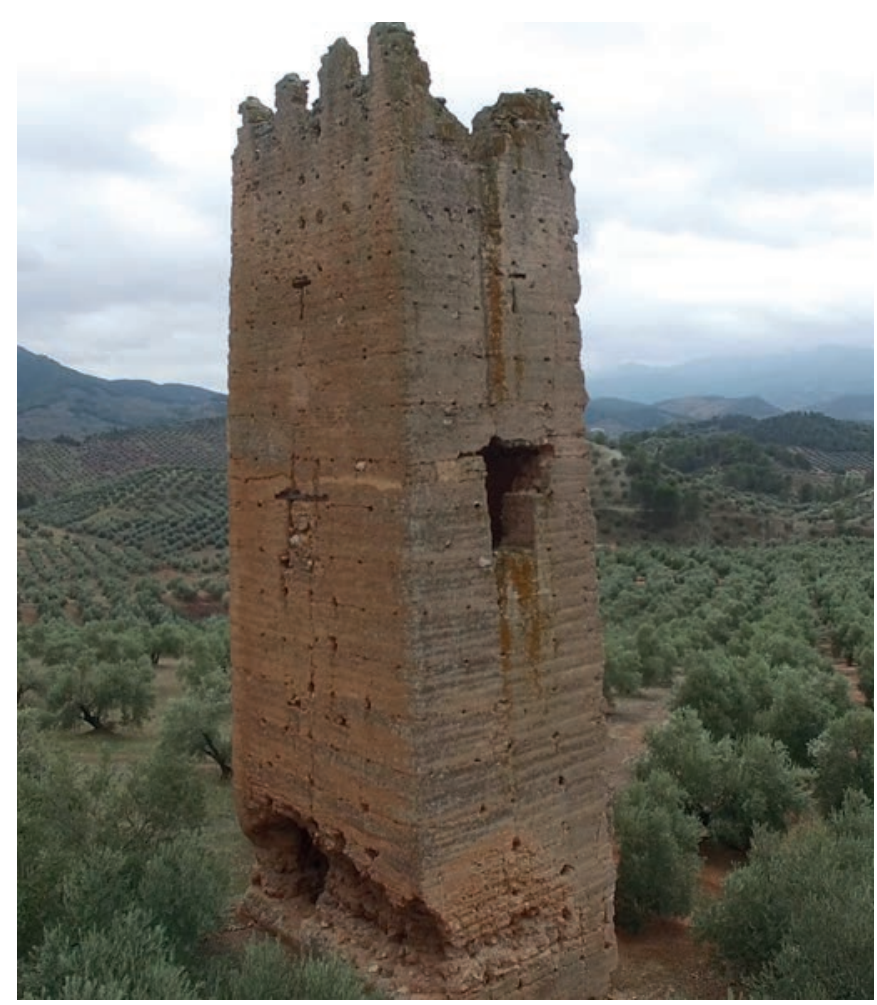

Figura 16. Torre sur de Santa Catalina. Su acceso se sitúa en la cara norte a una altura de $6,85 \mathrm{~m}$. Además en la cara este existe otro hueco con el dintel de madera original que fue cegado también con tapial. La torre aún conserva intactos todos los merlones en una de sus caras. Fuente: autor.

cima del monte. Tampoco muy cerca del camino principal. La ubicación domina visualmente $\mathrm{y}$ controla un área de influencia cercana, que suele ser un terreno relativamente llano, adecuado para la irrigación y cultivo. Esta superficie suele estar delimitada por colinas, barrancos, montañas, arboledas o caminos y está comprendida entre 182 y 415 hectáreas, como se puede comprobar en la relación de la tabla 2. Este dato avala la apreciación de Guichard cuando indica que el término qarīa, utilizado por Ibn ai-Abbār, solía designar suelos relativamente extensos con terrenos que se extendían cientos de hectáreas (Guichard 1988: 167). Ese patrón de asentamiento es el más común en

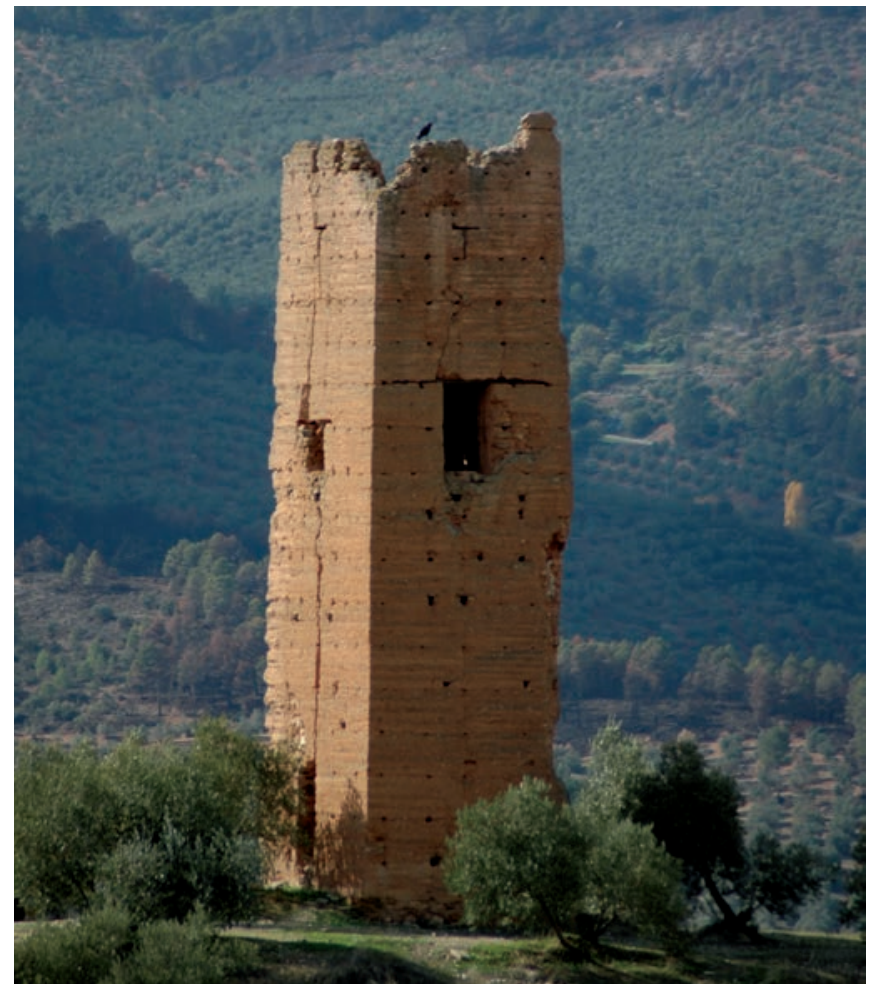

Figura 17. Torre norte de Sta. Catalina. También tiene dos aperturas o vanos originales situados a 7,18 m de altura. Tanto en esta torre como en la torre sur se aprecian los mechinales para introducir rollizos de sujeción de las plataformas de acceso. Son orificios pasantes toda la anchura del muro y que se han encofrado durante la ejecución de la fábrica para dejarlos previstos una vez terminada ésta. Fuente: autor.

este territorio segureño y aparece en las tres torres de Sta. Catalina, El Cardete, Altamira, La Torre, Gutamarta o Fuente de la Torre (Fig. 18).

- Se han realizado, hasta el momento, trece levantamientos fotogramétricos y topográficos de las torres que se conservan o de las que aún quedan restos. Estos dibujos han producido una exhaustiva documentación permitiendo su estudio estratigráfico, así como la caracterización y catalogación de estas estructuras (Fig. 19). Como consecuencia del trabajo gráfico se han podido obtener con precisión las dimensiones y métrica de cada torre, así como el tamaño de los cajones de tapial. Datos que se exponen en la tabla 3. 


\begin{tabular}{|c|c|c|c|}
\hline Denominación & $\left(\mathrm{m}^{2}\right)$ & (ha) & Tahúllas de tierra \\
\hline Torre y recinto EI Cardete & $3.557 .992,30$ & 355 & 3.195 \\
\hline Fuente de la Torre & $3.056 .777,00$ & 305 & 2.745 \\
\hline Torre Baja de Sta. Catalina & $1.821 .919,45$ & 182 & 1.638 \\
\hline Torre Norte de Sta. Catalina & $1.847 .024,82$ & 184 & 1.656 \\
\hline Torre Sur de Sta. Catalina & $2.100 .452,11$ & 210 & 1.890 \\
\hline La Torre (Valdemarín) & $3.116 .401,22$ & 311 & 2.799 \\
\hline Torre de Altamira & $4.150 .129,33$ & 415 & 3.735 \\
\hline Torre de Gutamarta & $3.405 .088,48$ & 340 & 3.060 \\
\hline
\end{tabular}

Tabla 2. Área de influencia asociada a las torres segureñas

\begin{tabular}{|c|c|c|c|c|c|}
\hline & Tam. ct & Dim. pl. & Dim. m & Alt. $n^{0}$ ct & Alt. \\
\hline EI Castillo & $0,7548 \mathrm{~m}$ & $6 \times 6$ & $4,40 \times 4,24$ & 8,5 & 6,60 \\
\hline Torre y recinto El Cardete & $0,8120 \mathrm{~m}$ & $8 \times 5$ & $6,70 \times 4,20$ & 16 & 13,00 \\
\hline Fuente de la Torre & $0,7142 \mathrm{~m}$ & $7 \times 5$ & $5,00 \times 3,57$ & -- & 2,60 \\
\hline Torre Baja de Sta Catalina & $0,7798 \mathrm{~m}$ & $11 \times 7$ & $8,60 \times 5,65$ & 18 & 14,05 \\
\hline Torre Sur de Sta Catalina & $0,7575 \mathrm{~m}$ & $7 \times 5$ & $5,30 \times 3,80$ & 20 & 15,15 \\
\hline Torre Norte de Sta Catalina & $0,7620 \mathrm{~m}$ & $7 \times 5$ & $5,00 \times 3,96$ & 19 & 14,50 \\
\hline La Torre (de Valdemarín) & $0,7700 \mathrm{~m}$ & $10 \times 6$ & $7,70 \times 4,62$ & 11 & 8,50 \\
\hline Torre de Góntar o de las Eras & $0,7984 \mathrm{~m}$ & $10 \times 6$ & $7,40 \times 4,80$ & 15 & 12,00 \\
\hline Torre del Agua & $0,7535 \mathrm{~m}$ & $10 \times 20$ & $7,50 \times 15,00$ & 21 & 15,70 \\
\hline Castillo de la Espinareda & $0,7809 \mathrm{~m}$ & -- & -- & -- & 7,00 \\
\hline Torre de Altamira & $0,8900 \mathrm{~m}$ & $10 \times 7$ & $8,80 \times 6,45$ & 10 & 9,00 \\
\hline Torre de Gutamarta & $0,8995 \mathrm{~m}$ & -- & $6,90 \times 5,75$ & -- & 3,30 \\
\hline Torres del castillo de Peñolite & $0,8050 \mathrm{~m}$ & $5 \times 5$ & $4,29 \times 4,17$ & 11 & 9,20 \\
\hline
\end{tabular}

Tabla 3. Métrica de las torres y medidas de los cajones de tapial. Tam. ct: Tamaño caja tapial (m=1 vara/cajón); Dim. pl.: Dimensión planta en varas/cajones; Dim. m: Dimensión planta torres en metros; Alt. no ct : Altura actual en número de cajones/varas de tapial; Alt.: Altura actual (m) 


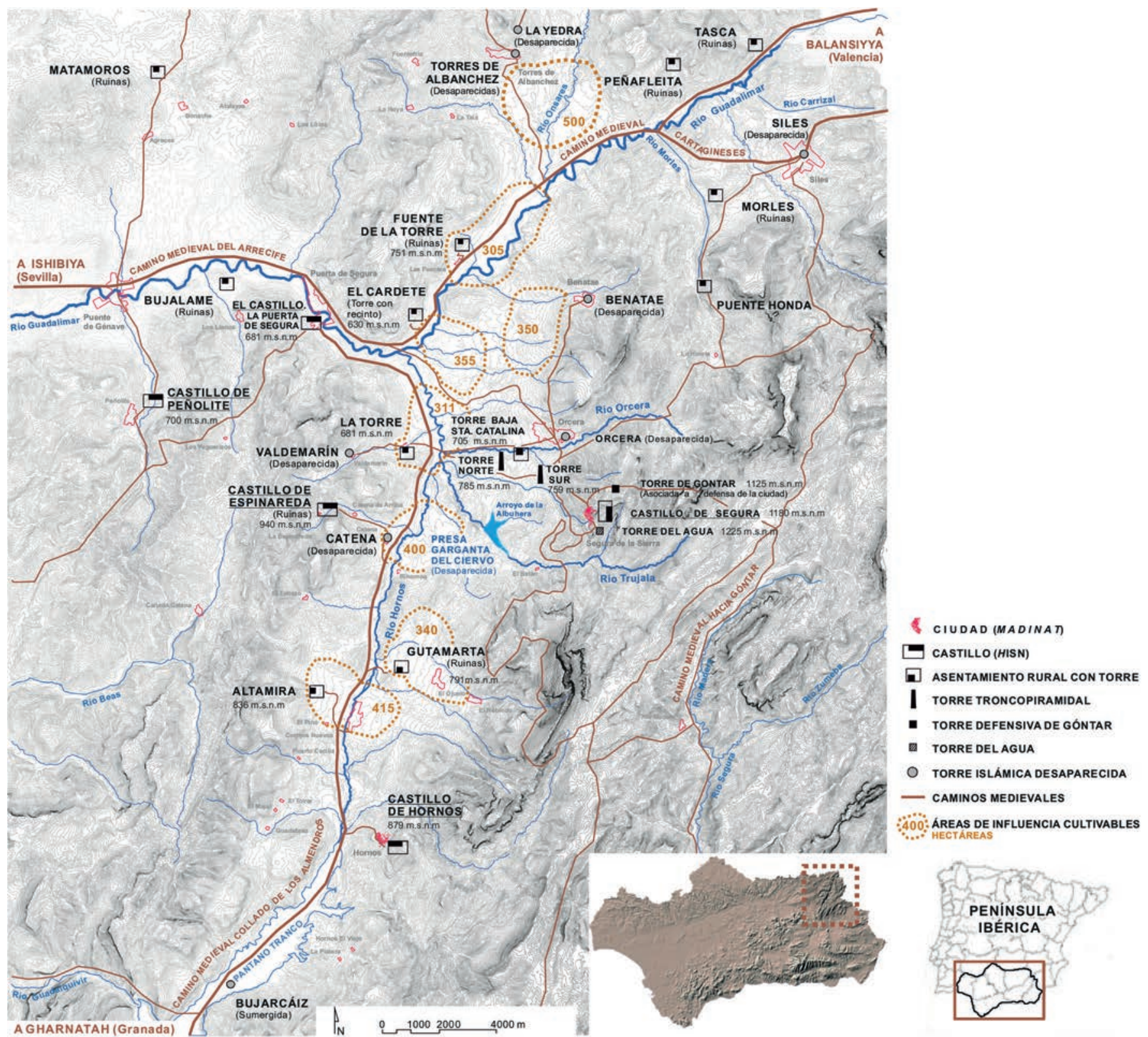

Figura 18. Territorio del 'amal de Šaqura con la ubicación de los diferentes ḥusūn, torres y asentamientos rurales relacionados con la topografía, el sistema hidrológico, los caminos medievales y las zonas cultivables dentro del área de influencia de cada una de las torres. Fuente: elaboración propia. 


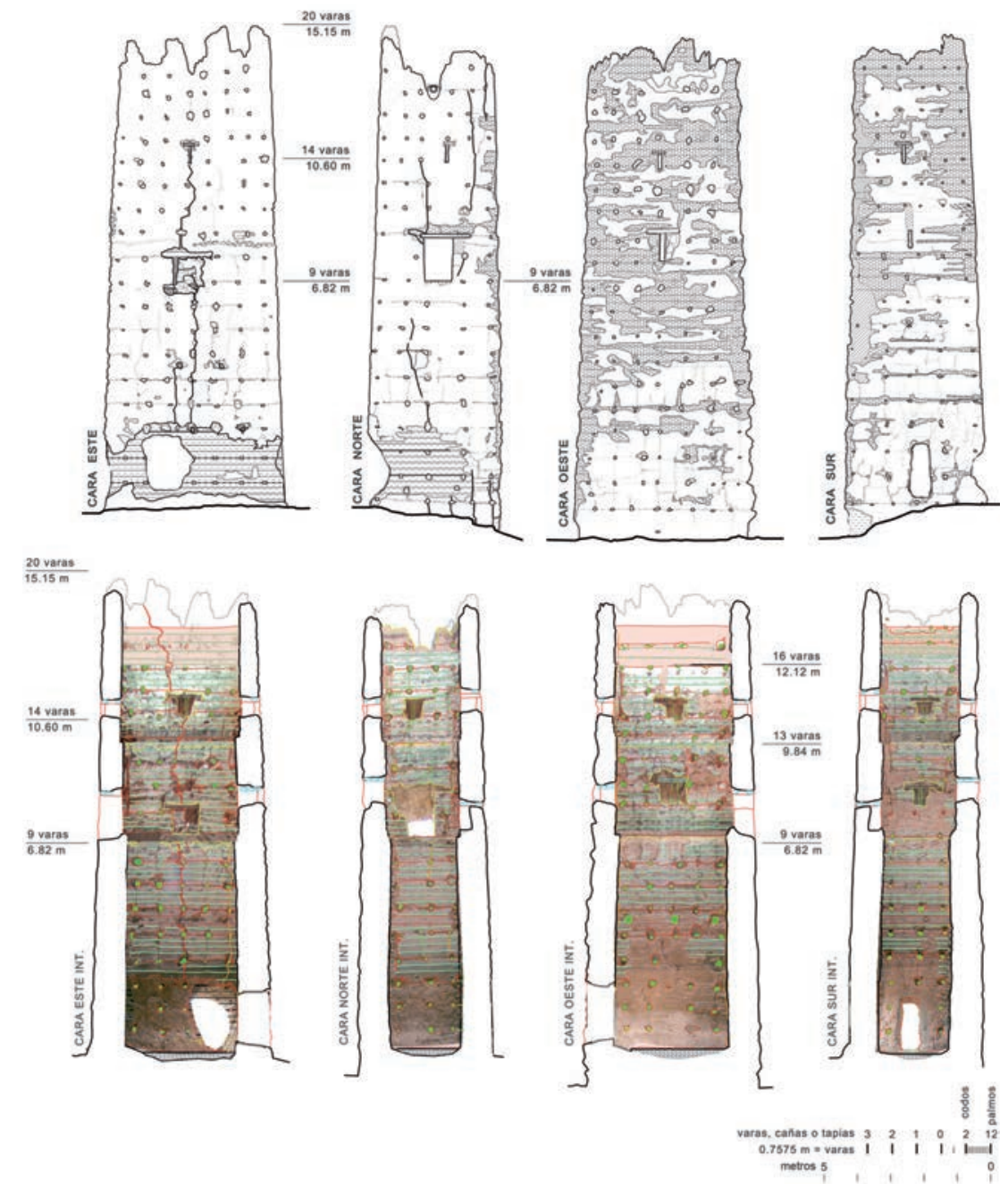

Figura 19. Levantamiento fotogramétrico de las caras exteriores y secciones interiores de la torre sur de Sta Catalina. Fuente: elaboración propia.
- Desde el punto de vista constructivo, se ha detectado la presencia en algunas torres (Puerta de Segura y Góntar) de rollizos embebidos en su fábrica colocados a modo de zuncho en los lugares donde cambia la sección del muro. Son varios maderos unidos entre sí que actúan como una especie de cadenas de atado o refuerzo en esos puntos de cambio de sección del muro. Este detalle constructivo, que ha salido a la luz en la investigación, prueba la calidad de ejecución y el desarrollo de la técnica empleada en estas torres rurales y demuestra que fueron construidas con precisos conocimientos técnicos sobre el funcionamiento de estas estructuras (Fig. 20).

- Respecto al trazado, replanteo y construcción de los muros de estas estructuras, otro resultado digno de destacar, obtenido en aquellas torres con más altura, es el ataluzado que tienen siempre tres de sus caras y que varía entre $1,3-3^{\circ}$. Este aspecto demuestra una clara intención de diseño que tenía que ser prevista y tenida en cuenta durante el proceso de replanteo y ejecución de los tapiales, uno de los cuales debía ser colocado inclinado durante el proceso de construcción de la torre para conseguir la inclinación deseada. El ataluzado de las caras es conocido en otras torres de tapial de al-Andalus pero nunca se menciona que la cuarta cara de la torre está a plomo, un claro indicio de una precisa voluntad constructiva. Los datos obtenidos se presentan en la tabla 4.

- La lectura estratigráfica de los paramentos ha permitido conocer la forma de acceder a dos de las torres de Sta. Catalina. En el caso de la torre norte su acceso se encuentra a 7,18 $\mathrm{m}$ de altura y en el caso de la torre sur a $6,85 \mathrm{~m}$. Estas considerables alturas hacían imposible que se pudieran alcanzar esas cotas con una sola escalera de madera debido a su peso y las dificultades de manejo que ello 

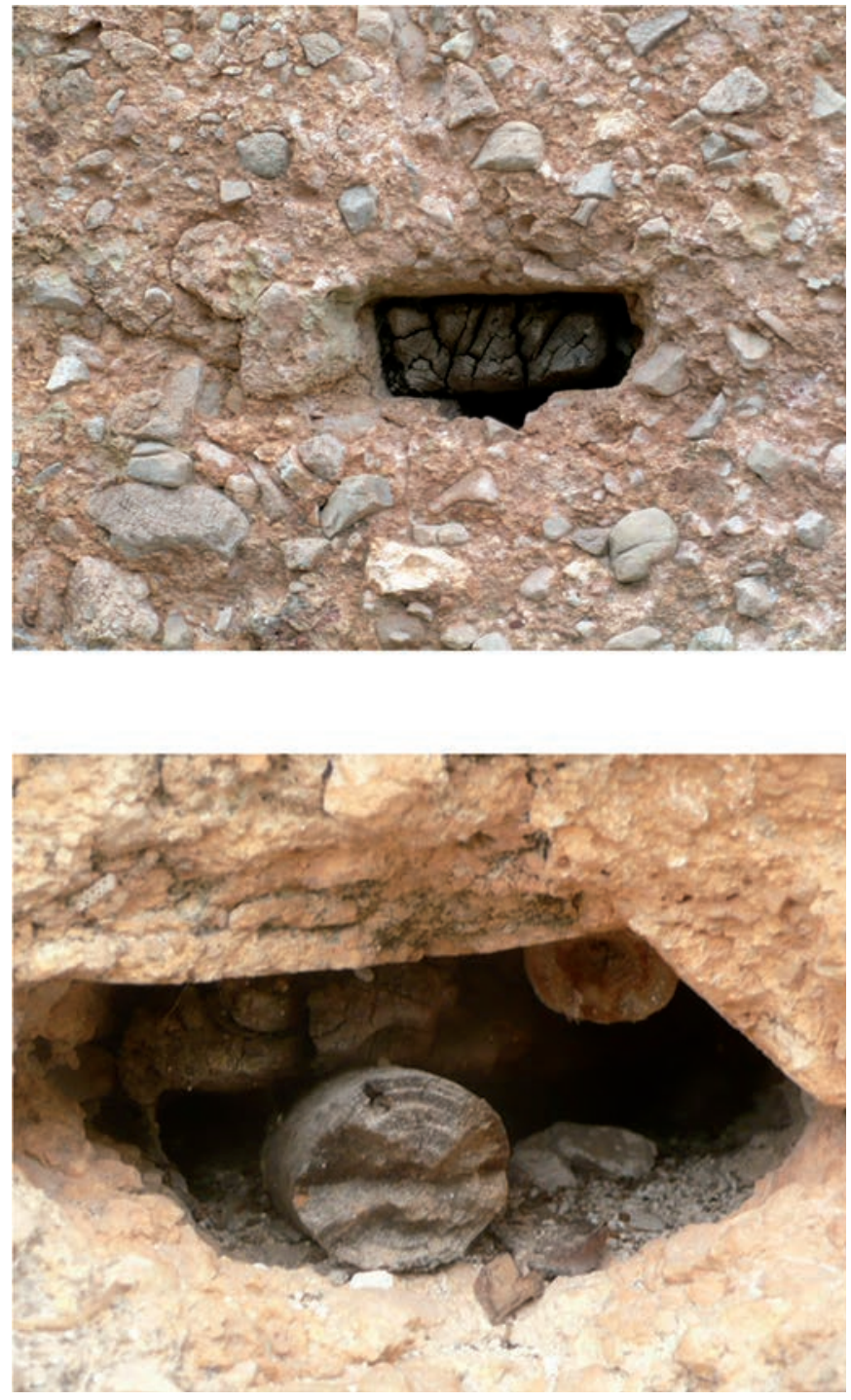

Figura 20. Media aguja rectangular dentro del tapial y conjunto de rollizos embebidos en la fábrica de la torre de Góntar, ubicadas en el punto donde el muro se escalona para cambiar de sección. Fuente: autor.

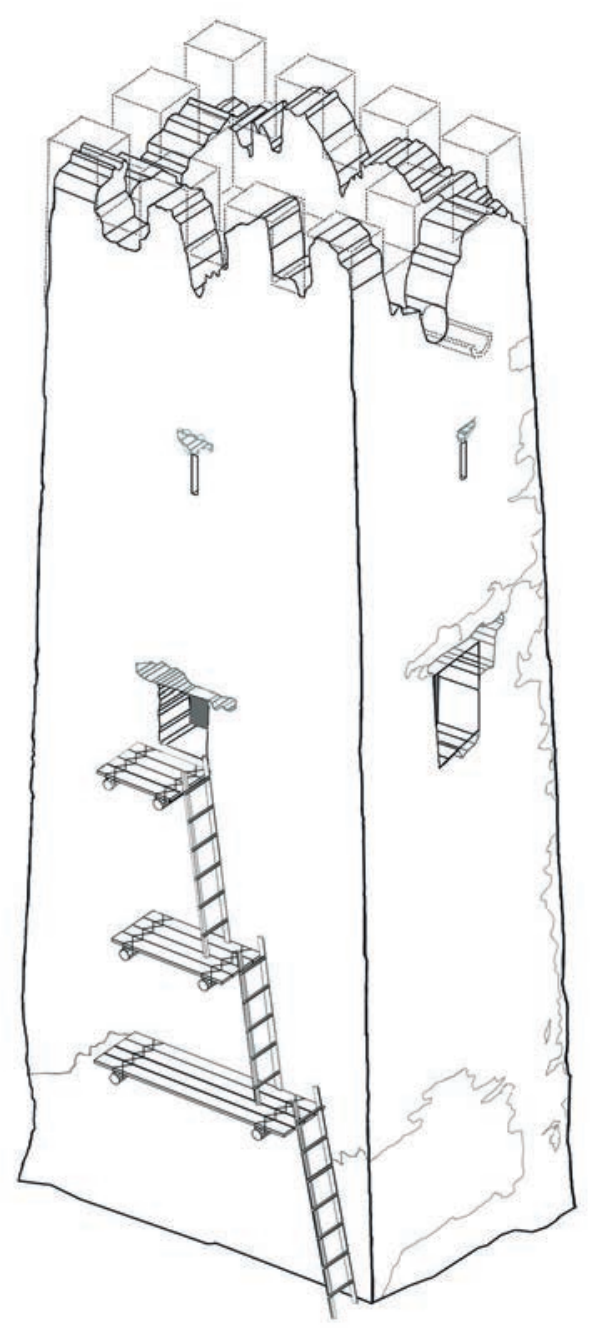

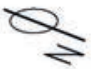

Figura 21. Reconstrucción volumétrica de la torre sur de Santa Catalina, en la que se ha grafiado la forma de acceso, que se realizaba por medio de un sistema de plataformas voladas soportadas por rollizos pasantes que eran introducidos en mechinales preparados durante la ejecución de la fábrica de tapial. Fuente: elaboración propia.

\begin{tabular}{|c|c|c|c|c|}
\hline & cara este & cara norte & cara oeste & cara sur \\
\hline Torre El Cardete & $3,03^{\circ}$ & $2,37^{\circ}$ & $1,95^{\circ}$ & a plomo \\
\hline Torre Sur de Santa Catalina & $2,46^{\circ}$ & $1,95^{\circ}$ & a plomo & $2,18^{\circ}$ \\
\hline Torre Norte de Santa Catalina & $1,77^{\circ}$ & $1,30^{\circ}$ & $2,31^{\circ}$ & a plomo \\
\hline Torre del Agua (en forma U) & Roca & $3,21^{\circ}$ & a plomo & $1,70^{\circ}$ \\
\hline Torre de Altamira & $2,17^{\circ}$ & $2,02^{\circ}$ & a plomo & $2,34^{\circ}$ \\
\hline Torres del castillo de Peñolite & $1,48^{\circ}$ & $2,93^{\circ}$ & $2,46^{\circ}$ & $1,86^{\circ}$ \\
\hline
\end{tabular}

Tabla 4. Ángulos de ataluzado de las diferentes caras de las torres 
entrañaría. Se ha podido determinar que el sistema de acceso era por medio de plataformas que, a modo de andamio anclado en mechinales previstos durante la ejecución del tapial, permitían un acceso lógico y racional (Fig. 21). Además también servirían para el registro interior de la torre, ya que los mechinales son pasantes, lo que quiere decir que las maderas introducidas en ellos podrían servir para plataformas tanto exteriores como interiores.

- Se han datado cronológicamente algunas de estas estructuras por medio de análisis de radiocarbono 14 a partir de muestras procedentes de elementos de madera y cal. Las pruebas realizadas en las torres sur y norte de Sta. Catalina, El Cardete, Peñolite y La Puerta de Segura han aportado una datación comprendida entre los años 1018 y 1155 . Un ensayo más en una costra de cal de la torre sur de Sta. Catalina, ha ofrecido el mismo rango de fechas (1026-1154). Por lo tanto, se puede afirmar que estas torres son anteriores a la conquista cristiana del territorio que se produjo alrededor de 1214 . Si se atiende a la fecha de datación más antigua (1018), podrían haber sido construidas durante la taifa de Segura. En su fecha más tardía (1155) significaría que se construyeron en pleno dominio almohade. Esta última datación parece la más probable, si a las fechas obtenidas en los análisis se suma la edad del árbol con el que se construyeron los elementos leñosos. En las torres de
Góntar y recinto del Cardete, se han encontrado restos de calicostrados con grafías y dibujos simulando falsos sillares (Fig. 22). Este aspecto ratificaría el dato cronológico, dado que esa peculiar decoración está atribuida a esa dinastía beréber.

- En la península ibérica se conservan ocho torres en tapial con características formales, tipológicas y constructivas muy similares, es decir, torres monofásicas, troncopiramidales, sin muro diafragma, ni bóvedas o arcos. Hay dos en la provincia de Albacete denominadas Torre de las Huertas en Molinicos y Llano de la Torre en Yeste; en la provincia de Valencia se encuentran las torres de Bofilla en Bétera, Godelleta, Espioca y del Señor en Serra. Hay constancia documental y arqueológica de que estas torres valencianas estaban asociadas a alquerías. Las torres norte y sur de Sta. Catalina en Orcera (Jaén) se conectan por su gran similitud a esos tipos de estructuras construidas en tapial en otros lugares de al-Andalus.

En general, la construcción de torres aisladas de alAndalus se relaciona, con la vigilancia y necesidad de defensa frente a la amenaza de un enemigo potencial, consecuencia directa de la presión de los reinos cristianos o a la confrontación entre sí de las distintas taifas andalusíes. Es decir, a estas estructuras se les asigna siempre una utilidad militar. Sin embargo en diferentes
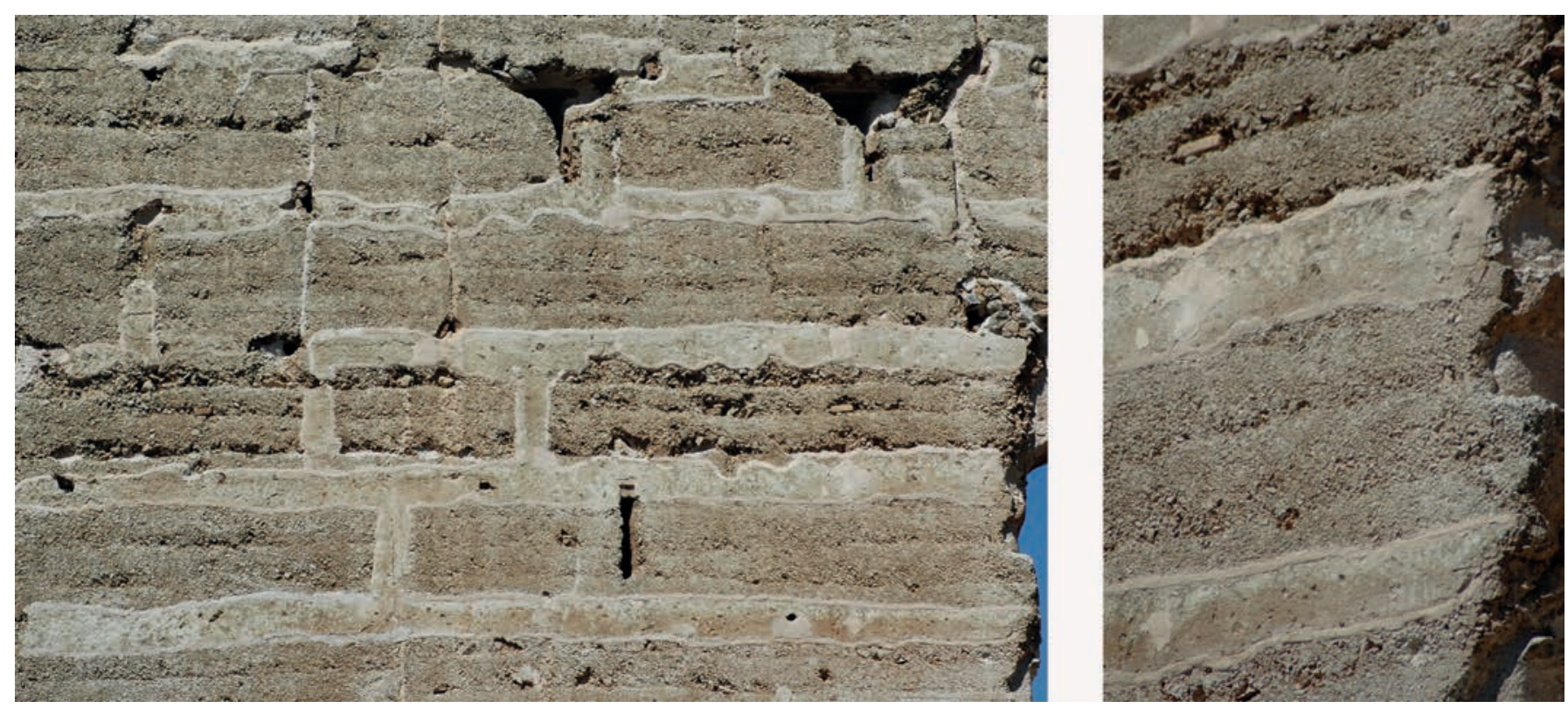

Figura 22. Calicostrados con falso despiece de sillares en la torre de Góntar. Detalle de las grafías y marcas recuperadas durante las labores de restauración realizadas en la torre en 2009. Fuente: autor. 
lugares, como la Alpujarra almeriense alejada de la frontera cristiano-musulmana, está documentada la presencia de torres en alquerías y asentamientos agrarios, lo que indica que este tipo de edificación en altura también pudiera estar relacionada con usos diferentes al militar, como la comunicación o el almacenamiento agrícola. Además la disposición de las torres y asentamientos segureños no sigue el esquema de anillos en torno a una ciudad, como ocurre en el entorno valenciano sino que se sitúan a lo largo de caminos y ríos. La mayoría de ellas son torres que no forman parte de castillos o recintos defensivos, ni son atalayas para dar aviso de lo que se descubre en la lejanía. Son torres que se sitúan en zonas bajas, a media altura de las colinas y en altozanos. La vigilancia estratégica del valle del Guadalimar, dada su altimetría y configuración orográfica, debió estar controlada por husūn situados en las cotas más altas que verían cualquier peligro mucho antes que las torres localizadas cerca de los cauces de los ríos. El único hiș̣n situado en las cotas bajas del valle habría sido el de la Puerta de Segura (579 m.s.n.m.) que, como su topónimo indica, controlaba el acceso oeste al valle por medio de la inundación del paso a través de una serie de compuertas ubicadas en el río Guadalimar (Fig. 23).

Por otro lado, independientemente del uso que pudieran tener estas torres, las estructuras de la Sierra de Segura tienen una alta calidad constructiva que las ha mantenido en pie sin intervenciones durante más de ocho siglos. Calidad de ejecución que no se improvisa. El nivel de conocimiento y homogeneidad en la ejecución de la técnica de tapial encontrado, no sólo en la Sierra de Segura sino en otros lugares dispersos y alejados de los núcleos principales de al-Andalus, podría indicar dos cosas: la gran versatilidad de una técnica importada del norte de África que, en menos de treinta años, permitió su diseminación y asimilación en todos los estratos de la sociedad andalusí o que el Estado almohade llegó a todos los rincones de al-Andalus, en un proceso de control progresivo del territorio.

Se argumenta que los señores andalusíes, que controlaron el territorio del Levante peninsular antes de la expansión de los almohades, desarrollaron un ambicioso programa de arquitectura que a menudo ha venido confundiéndose con la almohade (Navarro y Jiménez 2012).
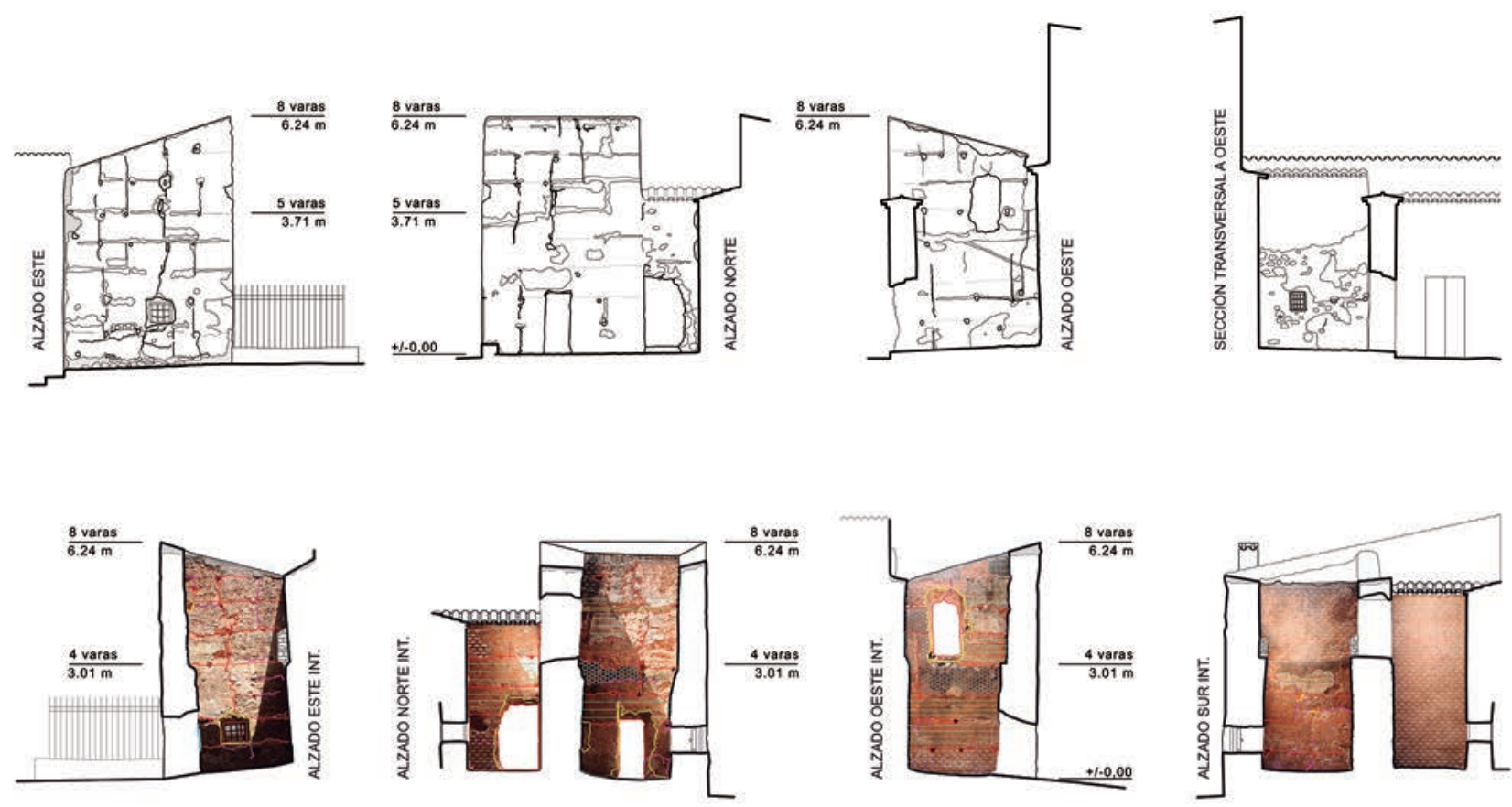

metros $5,1,1, i$

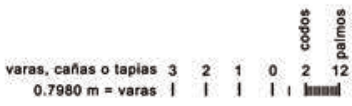

Figura 23. Levantamiento fotogramétrico de alzados y secciones de los restos de la torre El Castillo (La Puerta de Segura). Este castillo es el único hișn ubicado en una cota baja del valle y su función era, como el toponímico de la ciudad indica, controlar el paso hacia el interior del valle inundándolo por medio de una serie de compuertas ubicadas en el cercano río Guadalimar. Fuente: elaboración propia. 
Si estas torres en tierra fueron construidas por señores o por propietarios andalusíes de las tierras significaría que la técnica del tapial estaba lo suficientemente desarrollada como para ser independiente de factores locales que, en cualquier caso, siempre habrían dejado una impronta particular en la forma de construir, Sin embargo, estas diferencias no se aprecian. Si estas construcciones rurales fueron mandadas construir por el Estado almohade en asentamientos agrarios existentes como parte de sus programas de edificación, significaría que había unos criterios precisos de construcción pública en tierra que se aplicaron de forma relativamente planificada en todo el territorio para su explotación agraria, control o fiscalización. Esta cuestión deberá ser objeto de profundización en futuras investigaciones, para las que será especialmente necesaria la asociación de fuentes históricas, trabajo de campo, análisis y comparación de datos y resultados obtenidos por varias disciplinas.

\section{CONCLUSIONES}

A raíz de los estudios estratigráficos realizados, la presencia en los caliscostrados de grafías simulando falsos sillares, la comparación con ejemplos similares de alAndalus y los resultados obtenidos a partir de ensayos de radiocarbono 14 , se puede concluir que estos elementos de arquitectura en tierra de la Sierra de Segura son construcciones islámicas, datadas en el siglo XII, probablemente de origen almohade; lo que significa que, no solo en las ciudades sino también en el territorio rural de al-Andalus, la técnica constructiva de la tierra apisonada en tapia tuvo una enorme difusión y penetración, llegando a tener un alto grado de depuración técnica.

En la Sierra de Segura existen diferentes tipos de torres en tapial con formas diversas condicionadas por los distintos usos que debieron tener. Hay una torre con una clara función defensiva como es la de Góntar muy cerca del camino que protegía. La torre del Agua estaría relacionada con los recursos de abastecimiento de la ciudad. En lo que se refiere a la parte baja del valle la presencia de diversas torres aisladas parece señalar la presencia de asentamientos rurales de primer orden, diferentes de los husūn, tal y como se ha demostrado en la región valenciana o en las Alpujarras. Estas torres segureñas estarían asociadas a varios tipos de poblamientos rurales que podían ser alquerías (qurà), cortijadas (maŷāšir) o granjas (rahāal), todos ellos dedicados a actividades productivas de explotación de las tierras fértiles y accesibles. Por tanto, además del ocasional y posible refugio de campesinos, estas torres de la Sierra de Segura albergarían otras funciones, múltiples y complementarias, como serían las de siloalmacén, granero o eficaces elementos de comunicación entre núcleos cercanos, con los ḥusūn o con la medina. Algunos de esos poblamientos todavía mantienen sus usos rurales (Altamira, La Torre, Catena), otros los han mantenido hasta hace poco (Gutamarta) y varios se han convertido en núcleos urbanos (Orcera, Benatae). Una de las principales aportaciones de este trabajo ha sido revelar estos criterios de implantación de estas construcciones en tapial diseminadas. Los resultados obtenidos permiten concluir que el paisaje del 'amal de Šaqura estaría conformado por una medina principal con un castillo (Segura) junto con varios husūn como los de Espinareda, Peñolite o La Puerta de Segura; castillos rurales que estarían asociados a diversas qurà o alquerías distribuidas cerca de los tierras de labranza existentes en la parte baja del valle. Estos núcleos rurales serían nodos de un conjunto de infraestructuras, relacionadas entre sí y compuestas por terrenos cultivables, caminos, vías pecuarias y recursos hídricos.

A modo de conclusión, siempre provisional, se puede mantener que esta investigación sobre el sistema de torres existente en la Sierra de Segura está permitiendo profundizar en aspectos poco conocidos de este tipo de construcciones dispersas rurales. El trabajo está parametrizando y midiendo una serie de variables que inciden en la implantación de las mismas en el territorio como son: el emplazamiento, la cercanía a caminos y fuentes de agua, la elevación del terreno y su topografía, la superficie cultivable circundante, la distancia existente entre torres y asentamientos urbanos o los materiales y técnica constructiva, entre otros aspectos. La descripción y cuantificación de estas variables aporta un conocimiento y apunta hacia una metodología que servirá, junto con las necesarias actuaciones arqueológicas, para confirmar las hipótesis aquí expuestas, además de caracterizar con precisión los asentamientos rurales de al-Andalus.

Este trabajo es uno de los acercamientos con los que se puede tratar de alcanzar a conocer ciertos aspectos de la sociedad rural musulmana andalusí que los textos antiguos dejan casi en su totalidad en sombra y sobre la que sólo se puede arrojar algo de luz con multiplicidad de enfoques fragmentarios y pluridisciplinares. La comprensión que brindan los datos extraídos en este trabajo, concreto y siempre parcial, permitirá enfrentarse y abordar con una nueva perspectiva la 
implantación de estos elementos rurales construidos en tierra y diseminados en el territorio. El conocimiento, cada vez más profundo, de los entornos y relaciones de estas construcciones rurales permitirá introducir nuevos criterios y establecer innovadoras pautas metodológicas útiles en la investigación sobre el paisaje que dibujan estas arquitecturas dispersas.

\section{AGRADECIMIENTOS}

Agradecemos a aquellos compañeros que generosamente han compartido con nosotros sus conocimientos sobre arquitectura y construcción islámica en tierra, así como a investigadores de otras disciplinas que han aportado luz sobre aspectos que han complementado nuestras hipótesis. Este trabajo se ha beneficiado enormemente de los comentarios y sugerencias de los revisores anónimos, a los cuales también agradecemos sus anotaciones.

\section{BIBLIOGRAFÍA}

Acién Almansa, M. 1995: "La fortificación en al-Andalus", en R. López Guzmán (coord.), La Arquitectura del Islam Occidental, pp. 29-41. Lunwerg, Barcelona.

Acién Almansa, M. 2008: "Poblamiento y sociedad en al-Andalus: un mundo de ciudades, alquerías y husun", en J. I. de la Iglesia Duarte (coord.), Cristiandad e islam en la Edad Media hispana. XVIII Semana de Estudios Medievales, pp. 141-167. Instituto de Estudios Riojanos, Nájera.

Azuar Ruiz, R. 1981: Castillología medieval alicantina. Instituto de Estudios Alicantinos, Alicante.

Azuar Ruiz, R. 1994: "Las técnicas constructivas en al-Ándalus. El origen de la sillería y del hormigón de tapial”, en J. I. de la Iglesia Duarte (coord.), Actas de las V Semana de estudios medievales, pp. 125-142. Instituto de Estudios Riojanos, Nájera.

Azuar Ruiz, R. 2004: “Técnicas constructivas y fortificación almohade en alAndalus", en M. Valor Piechotta, J. L. Villar Iglesias y J. Ramírez del Río (eds.), Los almohades: Su patrimonio arquitectónico y arqueológico en el Sur de al-Andalus, pp. 57-74. Consejería de Relaciones Institucionales de la Junta de Andalucía, Sevilla.

Azuar Ruiz, R. 2005: "Las técnicas constructivas en la formación de alAndalus", Arqueología de la Arquitectura, 4, pp. 149-160.

Azuar Ruiz, R. 2008: "Castillos y espacios marginales de las ciudades en el Sarq al-Andalus (siglos XI-XIII)", en P. Cressier (ed.), Castrum 8. Le château et la ville. Espaces et réseaux (VIe-XIIIe siècle), pp. 89-108. Casa de Velázquez, Madrid.

Azuar Ruiz, R. y Ferreira Fernandes, I. C. 2014: "La fortificación del califato almohade", en P. Cressier y V. Salvatierra (eds.), Las Navas de Tolosa (1212-2012) Miradas cruzadas, pp. 395-420. Servicio de Publicaciones Universidad de Jaén, Jaén.

Azuar Ruiz, R., Lozano F. J., Llopis T. M. y Menéndez J. L. 1996: “El falso despiece de sillería en las fortificaciones de tapial de época almohade en al-Andalus", Estudios de Historia y Arqueología medievales, 6, pp. 245-278.

Ballesteros Linares, M. 2000: Comunicaciones y Defensas en la Comarca de Segura de la Sierra (siglos VII-XII), en Actas III Jornadas de Estudios de Frontera, pp. 103-118. Ayuntamiento de Alcalá la Real, Alcalá la Real (Jaén),

Barceló, M. 1984: "Un estudio sobre la estructura fiscal y procedimientos contables del emirato de Córdoba”, Acta Mediaevalia, 5-6, pp. 45-72.

Barrios Padura, A., Graciani García, A. y Núñez Arce, L. A. 2012: “Characterization of the rammed-earth structure of the Moon Castle in Mairena del Alcor (Seville, Spain)", en C. Mileto, F. Vegas y V. Cristini (eds.), Rammed Earth Conservation, pp. 263-267. Taylor y Francis Group, London.

Bazzana, A. 1980: "Eléments d'archéologie musulmane dans al-Andalus: caractères spécifiques de l'architecture militaire arabe de la region valencienne», Al-qantara: Revista de Estudios Árabes, I, pp. 339-364.

Bazzana, A. 2009: "Castillos y sociedad en al-Ándalus: cuestiones metodológicas y líneas actuales de investigación,” en A. L. Molina Molina y J. A. Eiroa Rodríguez (eds.), El castillo medieval en tiempos de Alfonso X el Sabio, pp. 11-14. Universidad de Murcia, Murcia.

Canivell, J. y Graciani García, A. 2015: "Caracterización constructiva de las fábricas de tapia en las fortificaciones almohades del antiguo Reino de Sevilla", Arqueología de la Arquitectura, 12: e025. doi: http://dx.doi. org/10.3989/arq.arqt.2015.003.

Caparrós, R. 2011: Arquitectura militar en la Sierra de Segura: Una interpretación paisajística y territorial, PH: Boletín del Instituto Andaluz del Patrimonio Histórico, 36, pp. 225-232.

Cerezo Moreno, F. y Eslava Galán, J. 1989: Castillos y atalayas del Reino de Jaén. Riquelme y Vargas Ediciones, Jaén.

Córdoba de la Llave, R. 2003: "La fortificación de hábitats en altura Almohades. La comarca del alto Guadiato (provincia de Córdoba) en los siglos XII y XIII", en P. L. Huerta Huerta (coord.), La fortificación medieval en la Península Ibérica, pp. 189-200. Fundación Santa María la Real, Centro de Estudios del Románico, Aguilar de Campoo.

Cressier, P. 1987: "El poblamiento medieval de la Sierra de los Filabres (Almería): primeros resultados", en Actas II Congreso de Arqueología Medieval Española. Madrid 1987, t. II, pp. 549-559. Asociación Española de Arqueología Medieval, Madrid.

Cressier, P. 1991: "Agua, fortificaciones y poblamiento. El aporte de la arqueología a los estudios sobre el Sureste peninsular", Aragón en la Edad Media, 9, pp. 403-428.

Cressier, P., Fierro, M. y Molina, L. (eds.) 2005: "Los almohades: problemas y perspectivas”, en Estudios árabes e islámicos. Monografías, 11, 2 v. CSIC, Madrid.

Cruz, E. de la, 1994: El reino Taifa de Segura. Diputación Provincial de Jaén, I. E. G., Jaén.

Eguaras Ibáñez, J. 2014: Ibn Luyūn: Tratado de Agricultura. Universidad de Almería, Almería.

Eslava Galán, J. 1989: Los castillos de la Sierra de Segura. Diputación Provincial de Jaén, I. E. G., Jaén.

Eslava Galán, J. 1999: Los castillos de Jaén. Universidad de Jaén, Papiro Ed., Osuna.

Fernandes, M. ${ }^{\mathrm{a}}$ y Correia, M. (coord.), 2005: Arquitectura de terra em Portugal. Argumentum, Lisboa.

Gallego Valle, D., Molero García, J., Castilla Pascual, F. J., Peña Ruiz, C. y Sanz Martínez, D. 2016: "El uso del tapial en las fortificaciones medievales de Castilla-La Mancha. Propuesta de estudio y primeros resultados de la investigación", en I. J. Gil-Crespo, Actas de las segundas jornadas sobre historia, arquitectura y construcción fortificada, pp. 215-234. Instituto Juan de Herrera, Fundación Cárdenas, Centro de Estudios José Joaquín de Mora, Madrid.

García San Juan, A. 2017: Evolución histórica y poblamiento del territorio onubense durante la época andalusí (siglos VIII-XIII). Servicio de Publicaciones de la Universidad de Huelva, Huelva.

Gil-Crespo, I. J. 2012: "Rammed earth walls in Serón de Nágima castle (Soria, Spain): constructive lecture", en C. Mileto, F. Vegas y V. Cristini (eds.), Rammed Earth Conservation, pp. 107-112. Taylor \& Francis Group, London.

Gil-Crespo, I. J. 2016: "Hacia una taxonomía constructiva de las tapias de tierra y fábricas encofradas históricas", Informes de la construcción, 67, (538). http://dx.doi.org/10.3989/ic.14.009. 
Glick, T. F. 1995: From Muslim Fortress to Christian Castle: Social and Cultural Change in Medieval Spain. Manchester University Press, Manchester.

Glick, T. F. 2007: Paisajes de conquista. Cambio cultural y geográfico en la España medieval. Universitat de València, Valencia.

Graciani García, A. 2009: "La técnica del tapial en Andalucía occidental", en A. Suárez Márquez (coord.), Construir en al-Andalus, Monografías del Conjunto monumental de la Alcazaba, 2, pp. 111-140. Junta de Andalucía, Consejería de Cultura, Sevilla.

Graciani García, A. y Tabales Rodríguez, M. A. 2008: "El tapial en el área sevillana. Avance cronotipológico estructural», Arqueología de la Arquitectura, 5, pp. 135-158.

Graciani García, A., Tabales Rodríguez, M. A., Alejandre Sánchez, F. J., Barrios Padura, A., Rodríguez García, R. y Ponce Ortiz de Insagurbe, M. 2005: "Revisión crítica de las analíticas sobre las fábricas de tapial en la muralla islámica de Sevilla", en Actas de las I Jornadas de Investigación en Construcción, vol. 1, pp. 213-222. Instituto Eduardo Torroja (CSIC), Amiet, Madrid

Guichard, P. 1988: "Le problème des structures agraires en al-Andalus avant la conquête chrétienne», en E. Cabrera (coord.), Andalucía entre Oriente y Occidente (1236-1492). Actas del V Coloquio Internacional de Historia Medieval de Andalucía, pp. 161-170. Diputación Provincial de Córdoba, Córdoba.

Guichard, P. 1990: L'Espagne et la Sicile musulmanes aux XIe et XIIe siècles, Pr. Univers. Lyon.

Gurriarán Daza, P. y Sáez Rodríguez, A. J. 2002: “Tapial o fábricas encofradas en recintos urbanos andalusíes", en Actas del II Congreso Internacional La Ciudad en al-Andalus y el Magreb, 1999, pp. 561-625. Fundación Legado Andalusí, Algeciras.

Huici Miranda, A. 2000: Historia politica del Imperio Almohade, 2 vols. Universidad de Granada, Granada.

Jaquin, P. A., Augarde, C. E. y Gerrard, C. M. 2008: "Chronological description of the spatial development of rammed earth techniques", International Journal of Architectural Heritage, 2, pp. 377-400.

López Elum, P. J. 1994: La alquería islámica en Valencia. Estudio arqueológico de Bofilla, siglos XI-XIV. Generalitat Valenciana, Valencia.

López Elum, P. J. 2002: Los Castillos Valencianos en la Edad Media (Materiales y técnicas constructivas). Biblioteca Valenciana, 2 vols. Valencia.

López Martínez, F. J. 1999: “Tapias y tapiales”, Loggia-Arquitectura y Restauración, 8, pp. 74-89.

López Martínez, F. J. 2012: "Restoration of rammed earth structures", en C. Mileto, F. Vegas y V. Cristini (eds.), Rammed Earth Conservation, pp. 2126. Taylor y Francis Group, London.

López Martínez, F. J. y Martínez López, J. A. 1999: “La muralla islámica de Murcia, el tramo de Verónicas: una obra de tapial", en Arquitectura de tierra: Encuentros Internacionales Centro de Investigación Navapalos, pp. 255-256. Ministerio de Fomento, Madrid.

Lozano Olivares, F. J., Menéndez Fuello, J. L., Azuar Ruiz, R. y Llopis García, M. a T. 1996: "El falso despiece de sillería en las fortificaciones de tapial en época almohade en al-Ándalus", Estudios de historia y de arqueología medievales, 11, pp. 245-278.

Magalhães, N. 2002: O Legado Arquitectónico Islâmico no Algarve. Instituto Português do Património Arquitectónico, Direção Regional de Faro, Faro.

Malpica Cuello, A. 1999: "El paisaje del mundo rural andalusí. Bases descriptivas para su análisis", PH: Boletín del Instituto Andaluz del Patrimonio Histórico, 27, pp. 146-153.

Malpica Cuello, A. 2003: Los Castillos en al-Andalus y la organización del territorio. Universidad de Extremadura, Cáceres.

Malpica Cuello, A. 2006: "Un asentamiento fortificado en la frontera nazarícastellana: Castril de la Peña", Studia histórica. Historia Medieval, 24, pp. 197-225.

Manzano Martínez, J. A. 1998: "Fortificaciones islámicas en la huerta de Murcia: Sector septentrional. Memoria de las actuaciones realizadas", Memorias de Arqueología, 7, pp. 405-419.

Márquez Bueno, S. y Gurriarán Daza, P. 2008: "Recursos formales y constructivos en la arquitectura militar almohade de al-Andalus", Arqueología de la Arquitectura, 5, pp. 117-121
Martín García, M. 2000: "Torres de alquería en la provincia de Granada", en A. Graciani, S. Huerta, E. Rabasa y M. A. Tabales (eds.), Actas del Tercer Congreso Nacional de Historia de la Construcción, pp. 651-664. Instituto Juan de Herrera, Madrid-Sevilla-Granada.

Martín García, M. y Martín Civantos, J. M. 2011: “Técnicas y tipologías constructivas de las fortificaciones medievales del poniente almeriense", en S. Huerta Fernández, I. Gil-Crespo, S. García y M. Taín (eds.), Actas del Séptimo Congreso Nacional de Historia de la Construcción, vol. 2, pp. 851-860. Instituto Juan de Herrera, Madrid.

Martínez Castro, A. 2003: "Breves notas sobre la funcionalidad de las torres islámicas de la campiña de Córdoba", Antiquitas, 15, pp. 65-83.

Martínez Castro, A. 2005: "La alquería, unidad de poblamiento básica en el al-Andalus rural", Boletín de la asociación provincial de Museos locales de Córdoba, 6, pp. 113-127.

Martínez Castro, A. 2015: "La Torre de Don Lucas (La Victoria, Córdoba), una torre de alquería en el sur de al-Andalus", Antiqvitas, 27, pp. 137-171.

Martínez Castro, A. y Tristell Muñoz, F. J. 1998: "Localizados los restos de la Torre de Albaén, un importante bastión almohade del noroeste de la Campiña cordobesa (término municipal de Córdoba)", Qurtuba, estudios andalusies, 3, pp. 256-257.

Mileto, C., Vegas López-Manzanares, F., Cristini, V. y García Soriano, L. 2012: "Restoration of rammed earth architecture in the Iberian Peninsula: Ongoing research", en C. Mileto, F. Vegas y V. Cristini (eds.), Rammed Earth Conservation, pp. 381-386. Taylor y Francis Group, London.

Mileto, C., Vegas López-Manzanares, F. y García-Soriano, L. 2013: “La técnica constructiva de la tapia en la arquitectura militar y defensiva en España. Variantes e invariantes", en S. Huerta-Fernández, F. S. López-Ulloa, (eds.), Actas del Octavo Congreso Nacional de Historia de la Construcción, vol. 2, pp. 681-687. Instituto Juan de Herrera, Madrid.

Mileto, C., Vegas López-Manzanares, F. y García-Soriano, L. 2017: "La restauración de la tapia monumental: pasado, presente y futuro", Informes de la Construcción, 69 (548), e231. http://dx.doi.org/10.3989/ic.16.160.

Mileto, C., Vegas López-Manzanares, F. y López, J. M. 2011: “Criterios y técnicas de intervención en tapia. La restauración de la torre Bofilla de Bétera (Valencia) “, Informes de la Construcción, 63, (523), pp. 81-96.

Navarro Palazón, J. y Estall i Poles, V. 2011: "La Alcazaba de Onda". El Legado Andalusi, 44, $4^{\circ}$ trim., pp. 74-83.

Navarro Palazón, J. y Jiménez Castillo, P. 2011: “Materiales y técnicas constructivas en la Murcia andalusí (siglos X-XIII), Arqueología de la Arquitectura, 8, pp. 85-120.

Navarro Palazón, J. y Jiménez Castillo, P. 2012: "La arquitectura de Ibn Mardanîsh: revisión y nuevas aportaciones”, en G. M. Borrás Gualis, B. Cabañero Subiza (coords.), La Aljafería y el Arte del Islam Occidental en el siglo XI, Actas del Seminario Internacional, pp. 291-350. Excma. Diputación de Zaragoza, Institución "Fernando el Católico", Zaragoza.

Pavón Maldonado, B. 1993: Ciudades y fortalezas lusomusulmanas: crónicas de viajes por el sur de Portugal. Instituto de Cooperación con el Mundo Árabe, Madrid.

Pavón Maldonado, B. 1998: “Tres villas fortalezas islámicas en la provincia de Jaén: Segura de la Sierra, Iznatoraz y Santiesteban del Puerto", Alqantara: Revista de estudios árabes, 19, 1, pp. 183-204.

Pavón Maldonado, B. 1999: Tratado de arquitectura hispanomusulmana. Ciudades y fortalezas. CSIC, Madrid.

Pérez Aguilar, L. G. 2013: "Problemas metodológicos en el estudio del mundo rural andalusí", Mediavalista, 14. https://doi.org/10.4000/medievalista.398

Quesada-García, S. y García-Pulido, L. J. 2013: "Las torres medievales del Valle de Segura de la Sierra o la construcción del paisaje. Análisis de la morfología y fábricas de las tapias de tierra y cal empleadas en las torres norte y sur de Santa Catalina”, en F. Jové Sandoval y J. L. Sáinz Guerra (coord.), Construcción con tierra. Pasado, presente y futuro. IX Congreso de Arquitectura de tierra. Tradición e Innovación, pp. 109-122. Cátedra Juan de Villanueva, Universidad de Valladolid, Valladolid.

Quesada-García, S. y García-Pulido, L. J. 2015a: "One of the Best Preserved Medieval Fortification Systems on the Frontier of al-Andalus: Segura de la Sierra (Spain)", Fort, 43, pp. 123-135. 
Quesada-García, S. y García-Pulido, L. J. 2015b: "El sistema de torres de origen medieval islámico en el Valle de Segura de la Sierra. La construcción de un paisaje", Boletín del Instituto de Estudios Giennenses, 212, pp. 99-165.

Quesada-García, S., García-Pulido, Luis J., Rodríguez Segura, A. y Romero Vergara, G. 2017: "Torre y recinto musulmán en Benatae (Sierra de Segura, Jaén) s. XII. Documentación, levantamiento, análisis gráfico y territorial", en M. Palma Crespo, Ma L. Gutiérrez Carrillo y R. García Quesada (eds.), Sobre una arquitectura hecha de tiempo. Actas del congreso ReUso, pp. 265-268. Universidad de Granada, Granada.

Rodríguez Navarro, P. 2018: La torres árabes de las alquerías valencianas. Tirant lo Blanc, Valencia.

Salvatierra Cuenca, V. 1999: Segura de la Sierra. Historia y monumentos de una villa medieval. Ayuntamiento de Segura de la Sierra, Segura de la Sierra.

Salvatierra Cuenca, V., Castillo Armenteros, J. C., Gómez Cabeza, F. y Visedo Jiménez, A. 2006: "Evolución de un territorio en época medieval. El valle del Hornos-Trujala (Segura de la Sierra)", en A. Gálvez (ed.), Proyectos de Investigación 2004-2005, pp. 11-82. Universidad de Jaén, Jaén.

Salvatierra Cuenca, V. y Gómez Cabeza, F. 2016: "La presa de la garganta del Ciervo, s. XII (Segura de la Sierra, Jaén, España): aportaciones a la ingeniería hidráulica andalusí”, Lvcentvm, 36, pp. 307-322.

Salvatierra Cuenca, V. y Visedo Jiménez, A. 2008: "Segura de la Sierra y el origen de la articulación de un territorio medieval", en P. Cressier (ed.), Castrum 8. Le château et la ville. Espaces et réseaux (VIe-XIIIe siècle), pp. 135-150. Casa de Velázquez, Madrid.

Simón García, J. L. 2011: Castillos y Torres de Albacete. Instituto de Estudios Albacetenses "Don Juan Manuel", Albacete.

Soler Estrella, A. 2009: "La técnica del tapial en las fortificaciones y despoblados de Sharq al-Andalus. Un estudio arquitectónico constructivo", en
S. Huerta, R. Marín Sánchez y R. Soler Verdú (eds.), Actas del Sexto Congreso Nacional de Historia de la Construcción, pp. 1361-1370. Instituto Juan de Herrera, Madrid.

Tabales Rodríguez, M. A. 2001: “Aportaciones de la arqueología medieval al conocimiento de las técnicas constructivas", en A. Graciani-García (ed.), La técnica de la arquitectura medieval), pp. 35-74. Universidad de Sevilla, Sevilla.

Terrasse, H. 1954: "Les forteresses de l'Espagne musulmane", Boletín de la Real Academia de Historia, 134, pp. 454-483.

Torres Balbás, L. 1934: "Las torres del Oro y de la Plata, en Sevilla", Archivo Español de Arte y Arqueología, 29, pp. 89-104.

Torres Balbás, L. 1985: Ciudades hispanomusulmanas. Instituto Hispano Árabe de Cultura, Madrid.

Valor Piechotta, M. 2004a: "Algunos ejemplos de construcciones defensivas almohades en la provincia de Sevilla”, en M. Valor Piechotta, J. L. Villar Iglesias y J. Ramírez del Río (eds.), Los almohades: Su patrimonio arquitectónico y arqueológico en el Sur de al-Andalus, pp. 145-179. Consejería de Relaciones Institucionales de la Junta de Andalucía, Sevilla.

Valor Piechotta, M. 2004b: "Las fortificaciones de la Baja Edad Media en la Provincia de Sevilla", Historia, Instituciones, Documentos, 31, pp. 687-700.

Valor Piechotta, M. 2009: "La arquitectura defensiva desde 1147 a 1300: algunos ejemplos de Andalucía Occidental", en A. L. Molina Molina y J. A. Eiroa Rodríguez (eds.), El castillo medieval en tiempos de Alfonso X el Sabio, pp. 196-210. Universidad de Murcia, Murcia.

Villegas Díaz, L. R. y García Serrano, R. 1976: "Relación de los pueblos de Jaén, ordenadas por Felipe II", Boletín del Instituto de Estudios Giennenses, 88-89, pp. 9-304.

Zamora Canellada, A. 2008: "Fortificaciones en la provincia de Segovia. Hacia un inventario", Estudios segovianos, 108, pp. 607-677. 